\title{
Ceres' Ezinu quadrangle: a heavily cratered region with evidence for localized subsurface water ice and the context of Occator crater
}

\author{
Jennifer E.C. Scully ${ }^{\mathrm{a}, *}$, D.L. Buczkowski ${ }^{\mathrm{b}}$, A. Neesemann ${ }^{\mathrm{c}}$, D.A. Williams ${ }^{\mathrm{d}}$, S.C. Mest ${ }^{\mathrm{e}}$, \\ R. Jaumann ${ }^{f}$, F. Preusker ${ }^{f}$, T. Roatsch ${ }^{f}$, M. Hoffmann ${ }^{n}$, A. Nathues ${ }^{n}$, M. Schaefer ${ }^{f}$, \\ A.I. Ermakov \\ a Jet Propulsion Laboratory, California Institute of Technology, 4800 Oak Grove Drive, Pasadena, CA 91109, USA \\ bohns Hopkins University Applied Physics Laboratory, Laurel, MD 20723, USA \\ ${ }^{c}$ Free University of Berlin, 14195 Berlin, Germany \\ d Arizona State University, Tempe, AZ 85004, USA \\ e Planetary Science Institute, Tucson, AZ 85719, USA \\ ${ }^{\mathrm{f}}$ German Aerospace Center (DLR), 12489 Berlin, Germany \\ g University of California, Los Angeles, CA 90095, USA \\ h University of Münster, 48149 Münster, Germany \\ ${ }^{i}$ NASA Goddard Space Flight Center, Greenbelt, MD 20771, USA \\ j Institute for Space Astrophysics and Planetology, National Institute for Astrophysics (INAF/IFSI), 00133 Rome, Italy \\ ${ }^{\mathrm{k}}$ Southwest Research Institute, Boulder, CO, USA \\ ${ }^{1}$ Bear Fight Institute, Winthrop, WA 98862, USA \\ $\mathrm{m}$ Georgia Institute of Technology, Atlanta, GA 30332, USA \\ ${ }^{n}$ Max Planck Institute for Solar System Research, 37007 Göttingen, Germany
} C.A. Raymond ${ }^{a}$, A. Nass ${ }^{f}$, K.H.G. Hughson ${ }^{g}$, T. Kneissl ${ }^{c}$, J.H. Pasckert ${ }^{h}$, O. Ruesch ${ }^{i}$, A. Frigeri ${ }^{j}$, S. Marchi ${ }^{k}$, J-P. Combe ${ }^{1}$, N. Schmedemann ${ }^{c}$, B.E. Schmidt ${ }^{m}$, H.T. Chilton ${ }^{m}$, C.T. Russell ${ }^{g}$,

\section{A R T I C L E I N F O}

\section{Article history:}

Received 8 August 2016

Revised 30 September 2017

Accepted 23 October 2017

Available online 10 November 2017

\section{Keywords:}

Asteroid Ceres

Asteroids, surfaces

Geological processes

Ices

Impact processes

\begin{abstract}
A B S T R A C T
Dawn is the first spacecraft to visit and orbit Ceres, the largest object in the asteroid belt and the only dwarf planet in the inner Solar System. The Dawn science team undertook a systematic geologic mapping campaign of Ceres' entire surface. Here we present our contribution to this mapping campaign, a geologic map and geologic history of the Ezinu quadrangle, located in the northern mid latitudes from 21-66 $\mathrm{N}$ and $180-270^{\circ}$ E. From our map, we reconstruct the geologic history of Ezinu quadrangle, which is dominated by impact cratering. Large impact craters that formed a few hundreds to tens of millions of years ago, such as Datan, Messor, Ninsar and Occator, are surrounded by ejecta and contain the products of mass wasting (hummocky crater floor material and talus material) and crater-wall collapse (terrace material). Two of these large impact craters are the sources of lobate flows, which we interpret as melt flows emplaced after the ballistically deposited ejecta. Morphological evidence suggests these lobate flows are rich in water-ice-bearing material that was excavated during the formation of the impact craters. There are only a few localized occurrences of lobate flows, suggesting that the water-ice-bearing source materials have restricted extents and/or are deeply buried within Ceres' subsurface. The quadrangle also contains a variety of linear features: secondary crater chains are formed by the impact of locally and globally sourced material and pit chains and grooves are formed by the collapse of surficial materials into sub-surface fractures. The Ezinu quadrangle contains the northern portion of Occator crater, which is the host crater of prominent bright regions called faculae. Our geologic analysis therefore also provides context for the future investigation of Occator and its intriguing faculae.
\end{abstract}

() 2017 Elsevier Inc. All rights reserved.

\footnotetext{
* Corresponding author.

E-mail address: jennifer.e.scully@jpl.nasa.gov (J.E.C. Scully).
} 


\section{Introduction}

\subsection{Dawn and Ceres}

Ceres is the largest object in the asteroid belt (mean diameter of $\sim 939 \mathrm{~km}$ ) and the only dwarf planet in the inner Solar System (Russell et al., 2016). Dawn is the first spacecraft to visit Ceres, which it began to orbit in March 2015. Pre-Dawn telescopic spectra gave insights into Ceres' surface composition and indicated the release of water vapor from Ceres' surface (King et al., 1992; Küppers et al., 2014; Larson et al., 1979; Lebofsky et al., 1981; McCord and Gaffey, 1974; Milliken and Rivkin, 2009; Rivkin et al., 2006). Moreover, Hubble Space Telescope observations and thermal evolution modeling suggested Ceres is at least partially differentiated (Castillo-Rogez and McCord, 2010; Drummond et al., 2014; McCord and Sotin, 2005; Parker et al., 2006; Thomas et al., 2005).

Further details about Ceres remained elusive until data was returned from the Dawn spacecraft's Framing Camera (FC) (Sierks et al., 2011), Visible-Infrared Mapping Spectrometer (VIR) (De Sanctis et al., 2011), Gamma Ray and Neutron Detector (GRaND) (Prettyman et al., 2011) and radio-science experiment (Konopliv et al., 2011). Initial Dawn observations found that Ceres has a mean density of $\sim 2162 \mathrm{~kg} / \mathrm{m}^{3}$, and is partially differentiated into a rocky core and comparatively water-ice-rich outer layer (Park et al., 2016; Russell et al., 2016). Data from VIR indicate that Ceres' global spectrum is best fit by a mixture of ammonia-bearing phyllosilicates, magnesium-bearing phyllosilicates, carbonates and an unidentified dark component (De Sanctis et al., 2015).

\subsection{Regional setting}

The high-resolution data of Ceres returned from Dawn, for example greyscale images with a spatial resolution of $\geq 35 \mathrm{~m} /$ pixel, facilitates detailed geologic mapping of Ceres' surface (see Section 2.1). Here we present a geologic map and a geologic history of Ezinu quadrangle, which is located in the northern mid latitudes from $21-66^{\circ} \mathrm{N}$ and $180-270^{\circ} \mathrm{E}$ (Fig. 1). This quadrangle contains a part of Hanami Planum, which is an elevated region that is $\sim 555 \mathrm{~km}$ wide and is centered at $15^{\circ} \mathrm{N}, 230^{\circ} \mathrm{E}$.

Detections of $\mathrm{H}_{2} \mathrm{O}$, attributed to exposed water ice, have been made in nine locations, all of which occur in Ceres' mid-northerly and mid-southerly latitudes (Combe et al., 2016; Combe et al., 2018a). Ceres' mid latitudes also contain a specific type of lobate flows, which are interpreted to be water-ice-rich on the basis of their morphological similarities to water-ice-rich flows on Earth, Mars and the icy satellites (Buczkowski et al., 2016; Schmidt et al., 2017). Furthermore, the increase in abundance of these lobate flows towards the poles is consistent with thermal modeling that shows surface and subsurface water ice to be more stable at the cooler poles than at the warmer equator (Hayne and Aharonson, 2015; Schmidt et al., 2017). Moreover, Ahuna Mons, a $\sim 4 \mathrm{~km}$ high dome, provides further evidence for water ice within Ceres' subsurface. This dome is interpreted to have formed by the ascent from depth of a cryo-magma, which may have incorporated brines in the melt component and/or water ice in the solid component (Ruesch et al., 2016). Crater morphologies and the simple-tocomplex transition diameter $(\sim 7.5-12 \mathrm{~km})$ also suggest that Ceres' outer layer is a mixture of icy and rocky materials (Hiesinger et al., 2016). In addition, the depths of the majority of craters (i.e., several kilometers) are inconsistent with viscous relaxation, indicating an average of $<30-40 \%$ by volume water ice in Ceres' outer layer (Bland et al., 2016; Fu et al., 2017).

Prominent bright areas were observed by Dawn on Ceres' surface, in particular within the floor of the 92-km-diameter Occator crater (e.g. Nathues et al., 2015; Russell et al., 2016). The northernmost portion of Occator crater is located in Ezinu quadrangle.
The bright areas in Occator crater are termed faculae and have a high single scattering albedo (0.67-0.80) in comparison to Ceres' average (0.09-0.11) (Li et al., 2016). Cerealia Facula is $\sim 9 \mathrm{~km}$ in diameter and is located in a $\sim 1 \mathrm{~km}$ deep pit in the center of the crater. Vinalia Faculae are located in the eastern crater floor (e.g. Nathues et al., 2015; Schenk et al., 2016). The faculae are dominantly composed of sodium carbonate and are proposed to be the residual product of the crystallization of impact-heated or preexisting brines sourced in the subsurface (De Sanctis et al., 2016).

Color mosaics are made from color images obtained from the seven color filters of Dawn's Framing Camera (spectral range of $440-965 \mathrm{~nm}$ and spatial resolution of $\sim 140 \mathrm{~m} /$ pixel) (Sierks et al., 2011). The specific filters from which the color mosaics are made are discussed in the figure captions of Figs. S1-S3. The dominant color characteristics of Ezinu quadrangle are grey in enhanced color (Fig. S1), purple in color composite A (Fig. S2) and green in color composite R (Fig. S3). These color characteristics are likely due to the magnesium-bearing and ammonium-bearing minerals that dominate the majority of Ceres' surface (Ammannito et al., 2016). Fresher craters within Ezinu quadrangle appear 'bluer' than their surroundings, because they are cyan-grey in enhanced color, blue in color composite A and cyan in color composite R. The ejecta and interiors of many fresher craters across Ceres' surface also display a 'bluer' color than the surrounding materials. This characteristic is attributed to their younger age, sublimation of water ice, differences in grain size or a combination of these processes (e.g. Krohn et al., 2016; Nathues et al., 2016; Schmedemann et al., 2016; Stephan et al., 2017). A detailed investigation of the effects that composition and grain size have on the color and spectral properties of the geologic units in Ezinu quadrangle cannot be completed by use of the Framing Camera color data alone, and requires the analysis of hyperspectral VIR data, which has orders of magnitude greater spectral resolution. Such an analysis will be detailed in an upcoming special issue about the compositional mapping of Ceres (Combe et al., 2018b).

\section{Methods}

\subsection{Data sources}

\subsubsection{Basemap}

The Dawn spacecraft observed Ceres during four stages of decreasing altitude: Approach $(>4400 \mathrm{~km})$, Survey $(4400 \mathrm{~km})$, High Altitude Mapping Orbit (HAMO, $1470 \mathrm{~km}$ ) and Low Altitude Mapping Orbit (LAMO, $385 \mathrm{~km}$ ). The basemap for our geologic mapping is a mosaic of clear filter Framing Camera LAMO images (Fig. 2). All mapped features were defined using this basemap, which has a spatial resolution of $\sim 35 \mathrm{~m} /$ pixel, is provided by the German Aerospace Center (DLR) and is produced by the methods outlined in Roatsch et al. (2017). The clear filter of the Framing Camera provides panchromatic images in the wavelength range of $450-920 \mathrm{~nm}$ (Sierks et al., 2011).

\subsubsection{Supplemental data to aid interpretation}

Although we defined the mapped features on the basis of the LAMO basemap, we used the following supplemental datasets to aid in our interpretation of these features:

- We used the shape model of Ceres to investigate the topography of the mapped features. DLR produced this shape model from clear filter Framing Camera HAMO images using the stereophotogrammetry (SPG) technique (Fig. 3) (Preusker et al., 2016). This HAMO-based SPG shape model has a lateral spacing of 60 pixels per degree, corresponding to $\sim 135 \mathrm{~m} /$ pixel, a vertical resolution of $<100 \mathrm{~m}$ and an intrinsic height accuracy of $\sim 12 \mathrm{~m}$. We use the shape model to provide us with an under- 


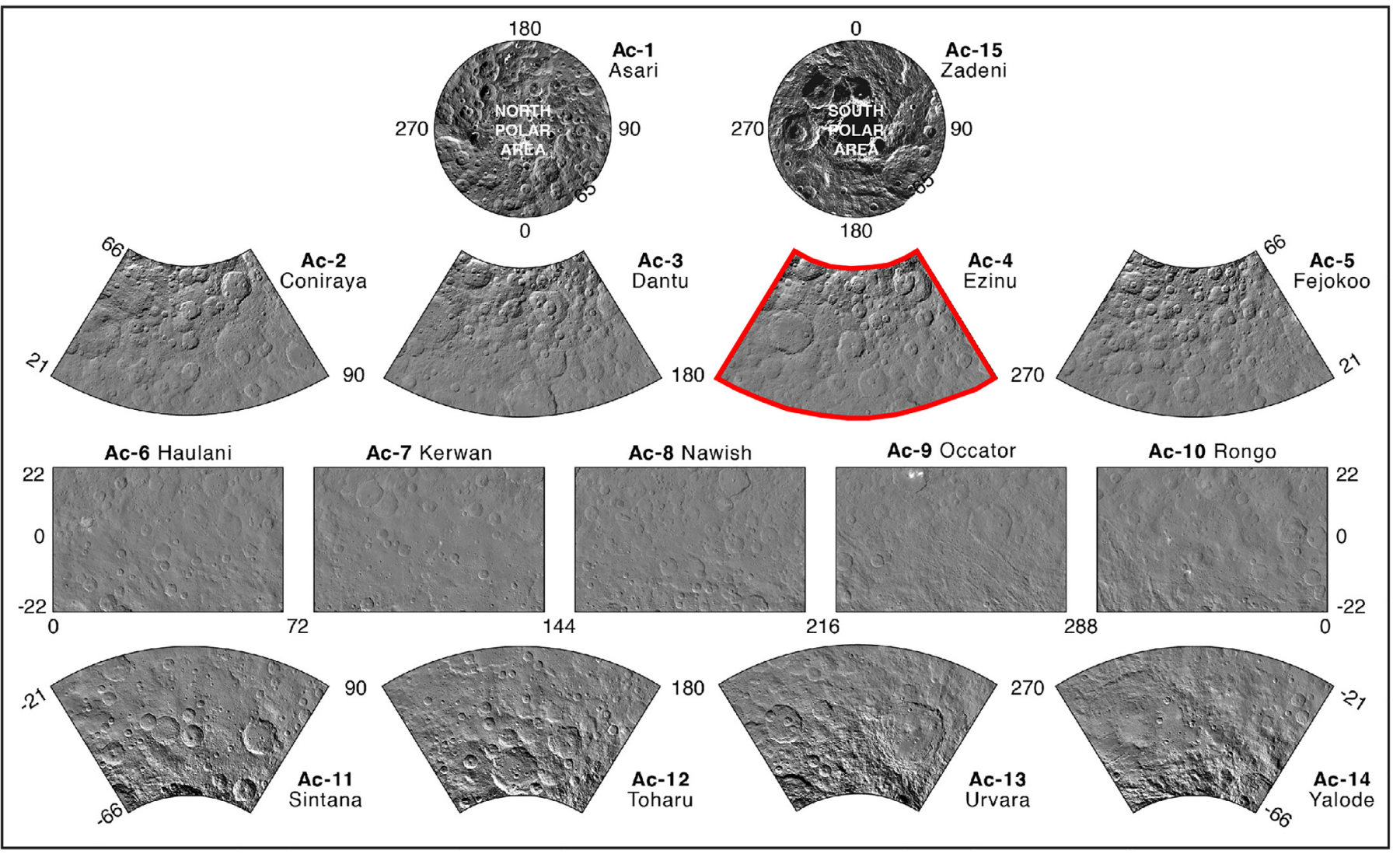

Fig. 1. The fifteen-quadrangle scheme developed by the Dawn science team (see Section 2.2). The focus of this study is the Ezinu quadrangle. This figure is adapted from Roatsch et al. (2016).

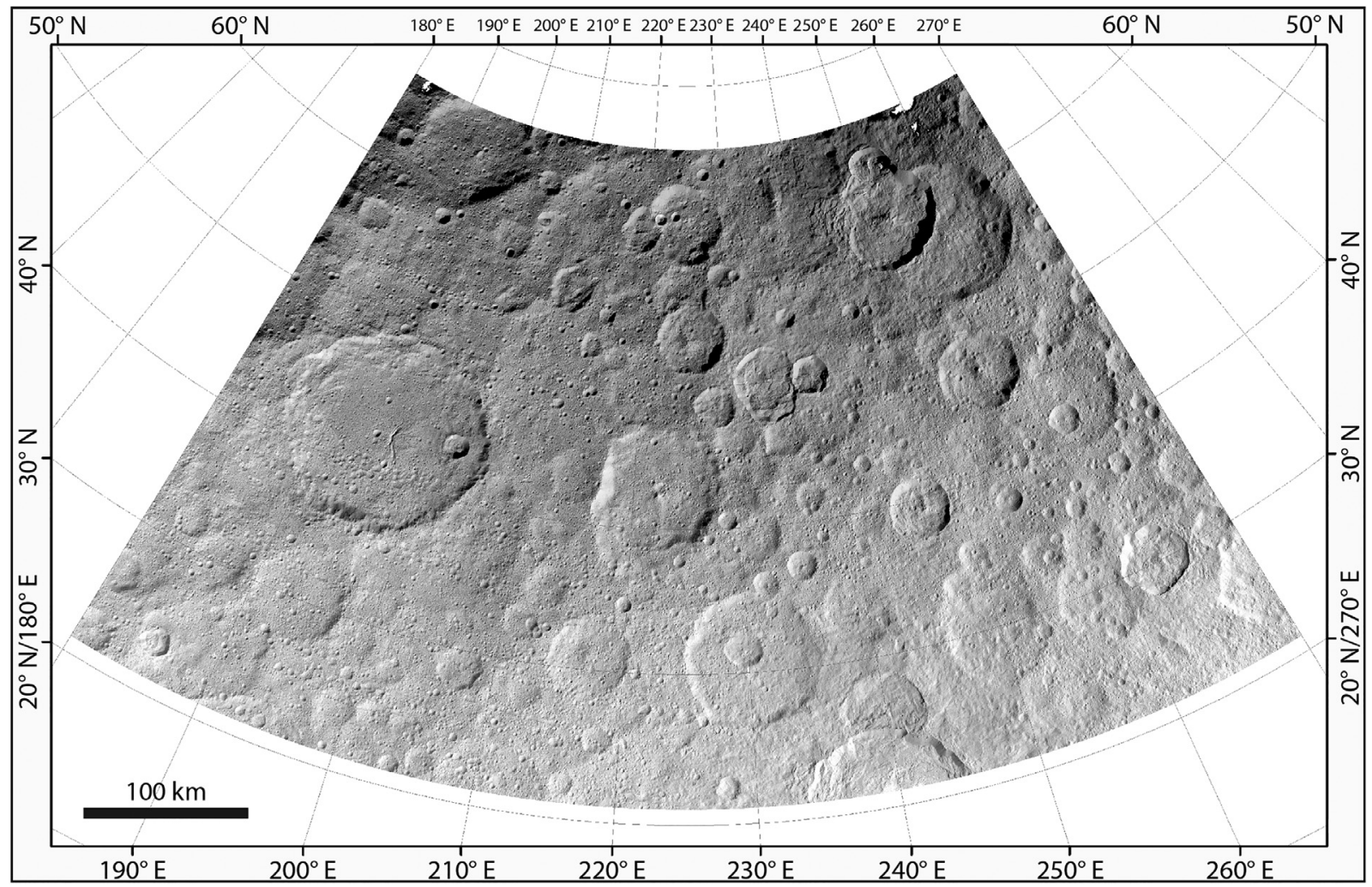

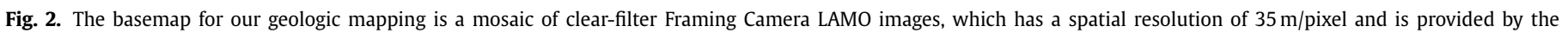

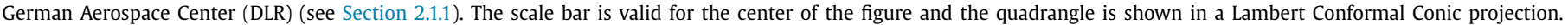




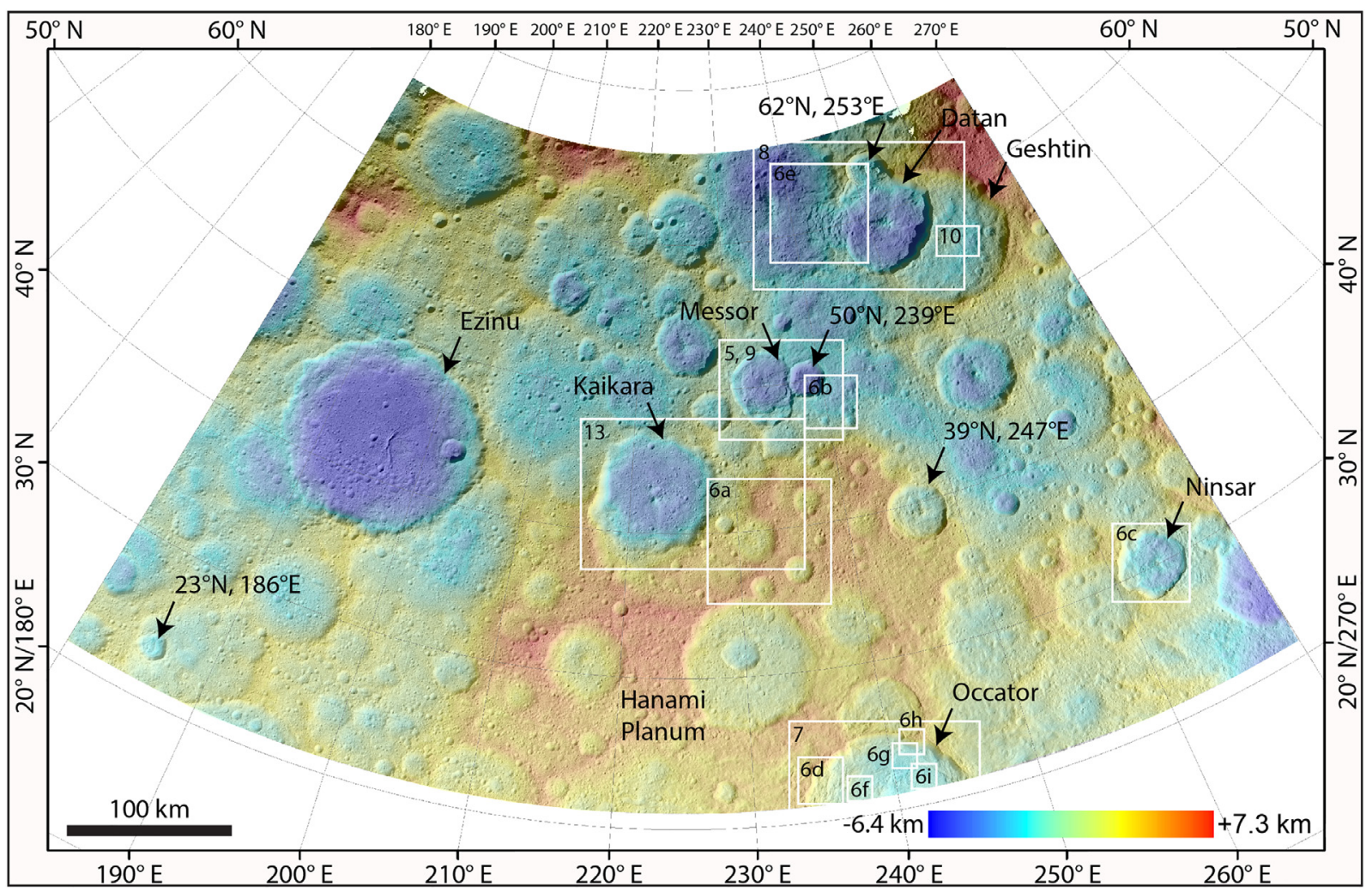

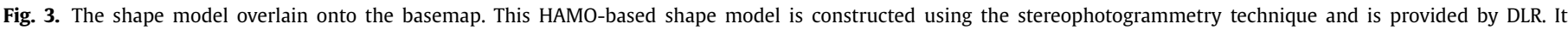

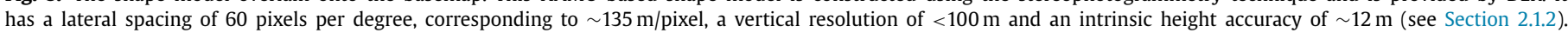

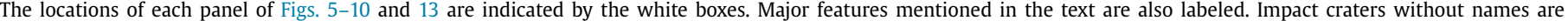
labeled by their center coordinates. The scale bar is valid for the center of the figure and the quadrangle is shown in a Lambert Conformal Conic projection.

standing of the quadrangle in three dimensions. We also create topographic profiles using this shape model (see Section 2.2).

- We used the photometrically corrected mosaic of clear filter Framing Camera HAMO images (spatial resolution of $\sim 140 \mathrm{~m} /$ pixel, provided by DLR) to interpret whether the dark or bright appearance of regions in the basemap is controlled by their albedos or by the solar illumination conditions under which they were observed (Fig. S4). Only albedo differences should be visible in the photometrically corrected mosaic. Here we define a sub-unit as 'dark', 'intermediate' or 'bright' with reference to their pixel values in the photometrically corrected mosaic viewed in ArcMap 10.3 (see Sections 2.2 and 3.2).

\subsection{Mapping approach}

The Dawn science team conducted a systematic geologic mapping campaign at Ceres, similar to that undertaken at Vesta (e.g. Williams et al., 2014; Yingst et al., 2014). To facilitate this campaign, the surface of Ceres was divided into fifteen quadrangles (Fig. 1) (Roatsch et al., 2016). Quadrangle names are based on a quadrangle's most prominent crater. Craters were named for gods and goddesses of agriculture/vegetation from world mythology, and feature names were taken from world agricultural festivals (Roatsch et al., 2016). For example, Ezinu is a Sumerian goddess of the grain.

Each quadrangle was mapped by a lead mapper, supported by the lead mappers of neighboring quadrangles and other members of the Dawn science team. The lead mappers ensured the consistency of geologic units and geologic features across quadrangle boundaries. We primarily used ESRI ArcMap 10.3 software, which facilitates the georeferencing of the mapping to the underlying datasets and provides tools for geometric analyses. On the basis of
United States Geological Survey (USGS) guidelines and the spatial resolution of our basemap (see Section 2.1.1), we mapped at a scale of $1: 100,000-1: 125,000$. In this manuscript, the geologic map is shown at a scale of $1: 2,000,000$ (Fig. 4) and at scale of 1:1,000,000 in the supplemental map sheet (Fig. S5). We also used ESRI ArcScene 10.3 to produce perspective views of the data. In addition, we used both ESRI ArcMap 10.3 and the USGS ISIS (Integrated Software for Imagers and Spectrometers) to obtain topographic profiles for three-dimensional analyses. We used map symbols based on the standardized symbology recommended for planetary geologic features by the USGS (Federal Geographic Data Committee, 2006). Further details about the geologic mapping strategy are included in the introductory paper to this special issue (Williams et al. 2018).

\subsubsection{Derivation of absolute model ages}

We derived absolute model ages for geologic units by measuring the diameter and number of craters in each geologic unit using ESRI's ArcGIS and the latest version of the add-in "CraterTools", developed by Kneissl et al. (2016, 2015, 2011). This tool allows for map-projection independent, accurate measurements of crater diameters and areas. We created best-fit crater ellipses by defining three points on the crater rim on projected image data. CraterTools then internally re-projected the crater into an equidistant sinusoidal projection by using its center coordinates as the projection center to calculate the undistorted crater diameter along the longitude. The areas used to derive model ages either corresponded to an entire mapped geologic unit or to a ring of ejecta surrounding a crater, where the inner ring margin was an idealized crater ellipse and the outer ring margin was set at one crater radius from the idealized crater ellipse. Crater material often extends past the outer ring margin, but using this margin minimized the number of background craters counted by accident. We include a figure illus- 


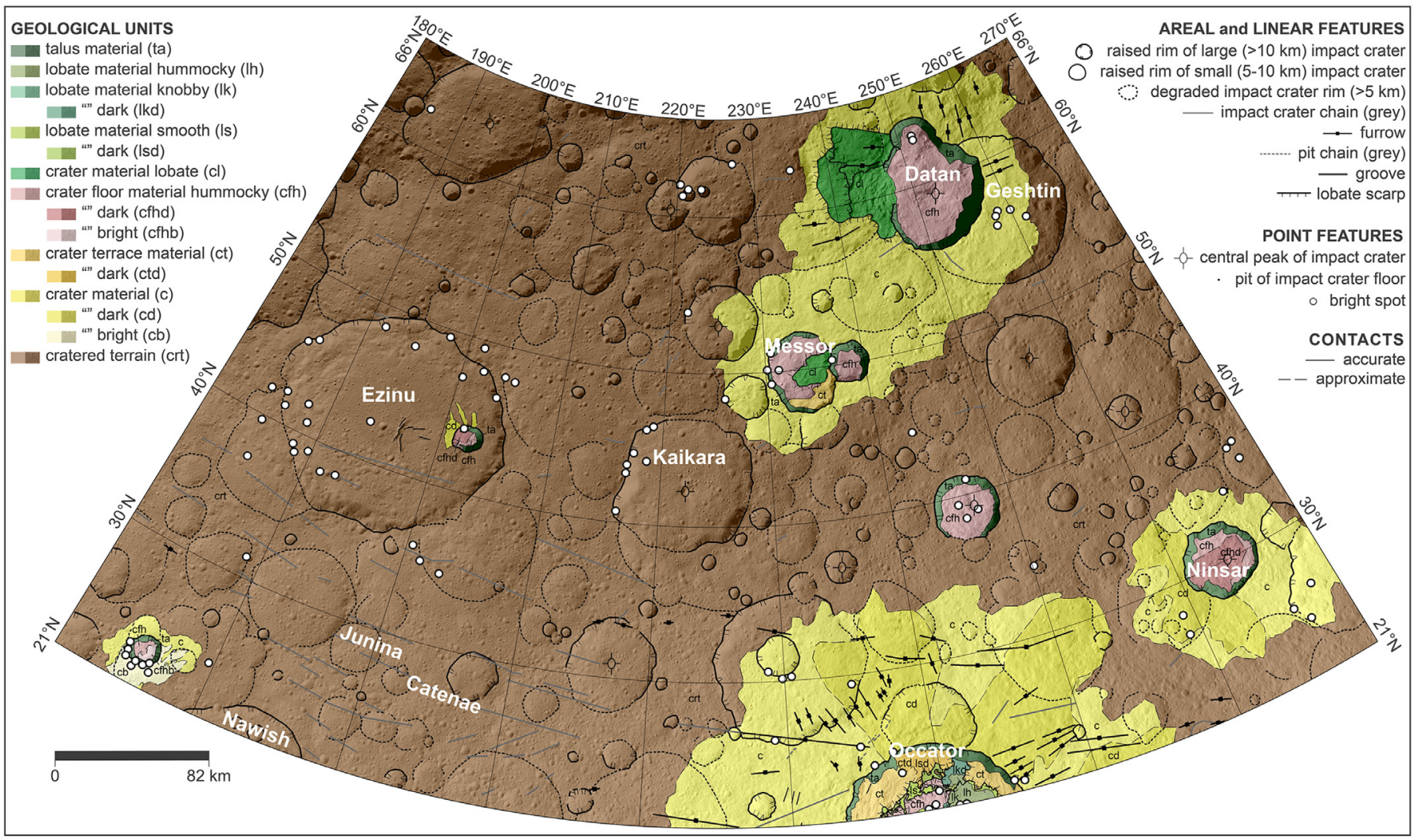

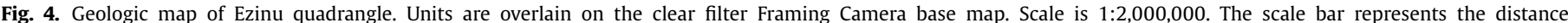

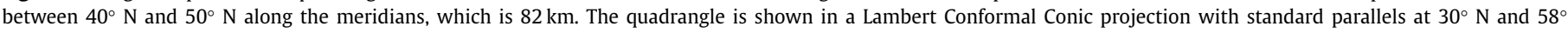
N. A high-resolution and large-format version of this geologic map is included in the supplementary material (Fig. S5).

trating the crater count area around Messor crater as an example of this approach (Fig. 5). The figures illustrating the crater count areas of the remaining geologic units are included in the Supplementary Material (Figs. S6-S11).

Importantly, we excluded areas that exhibit obvious secondary crater clusters or chains from the count areas. For example, we excluded a secondary crater cluster within Ezinu crater (Fig. S7). Our measurements most likely contain some randomly distributed, and thus unrecognizable, secondary craters. From analyses of the crater size-frequency distribution plots, we were not able to determine if secondary craters dominate the crater population below a certain crater diameter, which would manifest itself in the form of higher slope exponents below this diameter. However, this interpretation depends on the shape (slope exponent) of the scaled or modeled production functions and can therefore not be considered an unequivocal parameter.

We fit the resulting curve of crater diameter versus crater frequency to crater size-frequency distribution curves based on the two separate Cerean chronology systems currently available: the lunar-derived chronology system (hereafter denoted by a superscript ' $L$ ') and the asteroid-flux-derived chronology system (hereafter denoted by a superscript 'A') (for additional details see Hiesinger et al., 2016). The absolute model ages are expressed as a likelihood function (Michael et al., 2016) and all of the crater sizefrequency distribution curves are included in the Supplementary Material (Figs. S12-S13). Above each crater size-frequency distribution plot are the results of two independent randomness analyses (Michael et al., 2012). We present the statistical errors of the model ages to two decimal digits in Table 1 . However, it is important to note that the unquantifiable intrinsic errors of both chronology systems are much greater than the quantifiable statistical errors.
Thus, in the main text we do not include the statistical errors and present the model ages as ' $\sim \mathrm{X}$ Ma'.

The model ages for the same unit derived from the two chronology systems can differ substantially, especially for the older units because the two chronology functions diverge for progressively greater ages and are most separated for surface ages $\sim 3500$ Ma and older (Hiesinger et al., 2016). For example, the model ages derived for the cratered terrain in Ezinu quadrangle are $\sim 3380 \mathrm{Ma}^{\mathrm{L}}$ or $\sim 4120 \mathrm{Ma}^{\mathrm{A}}$ (Table 1 ). However, the stratigraphic time periods into which we divide the geologic history of this quadrangle are based on superposition relationships between the geologic units and not on their model ages. In addition, the two sets of model ages for each geologic unit always fall within the same stratigraphic time period (see Section 4.2 for details about the stratigraphic time periods we use). Therefore, despite returning different absolute model ages, the two different chronology systems do not complicate the geologic history we derive for the quadrangle.

\section{Results}

\subsection{Geologic map of Ezinu quadrangle}

To account for the sizes at which the geologic map of Ezinu quadrangle is displayed, we set the scale of the map figure to $1: 2,000,000$ (Fig. 4) and we set the scale of the supplemental map sheet to $1: 1,000,000$ (Fig. S5). To avoid these geologic maps appearing cluttered, on account of mapping the quadrangle at a scale of 1:100,000-1:125,000, we only display: (i) geologic units and surface features that are $\geq 5 \mathrm{~km}$ in size; (ii) linear features that are $\geq 5 \mathrm{~km}$ long and spaced at distances of $\geq 3 \mathrm{~km}$; (iii) crater wall and rim units that are $\geq 3 \mathrm{~km}$ wide; and (iv) point features that are spaced at distances of $\geq 3 \mathrm{~km}$. When linear features and point 

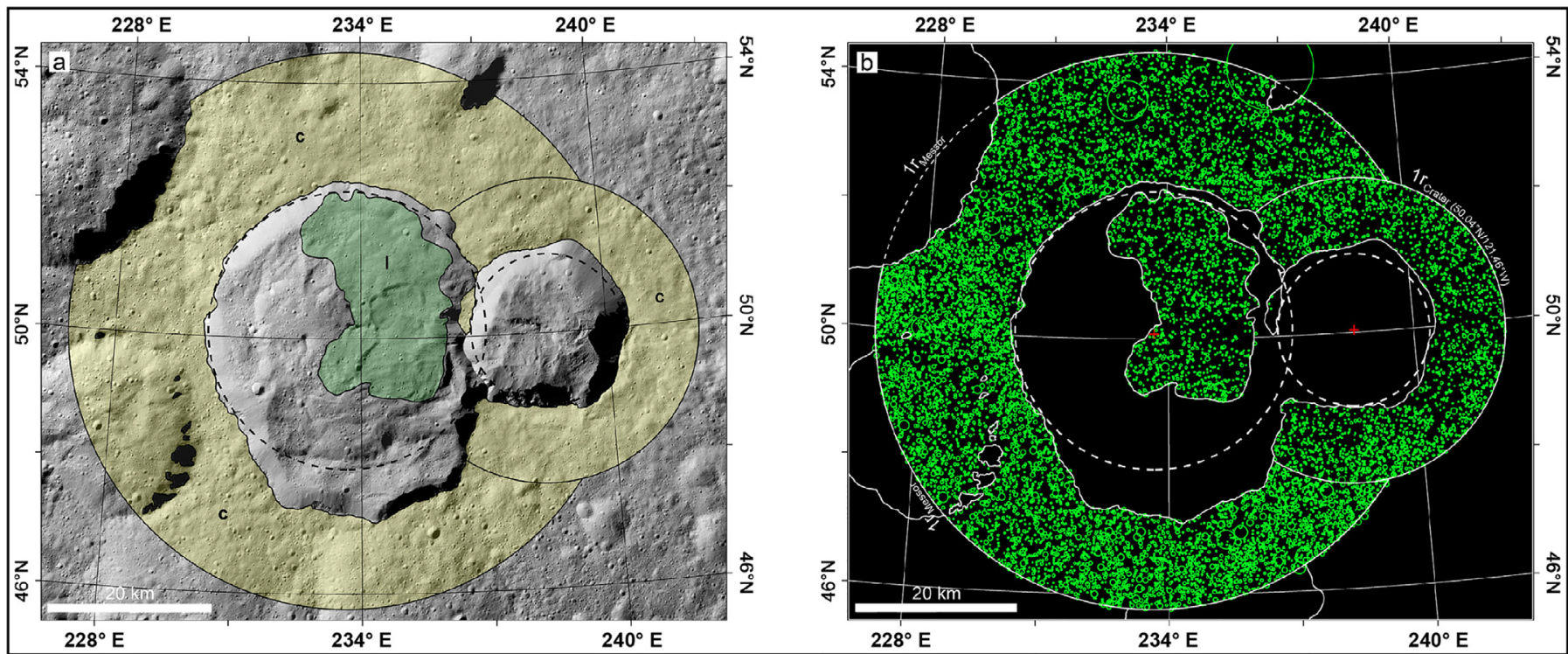

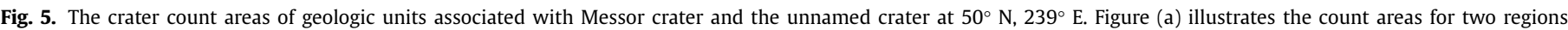

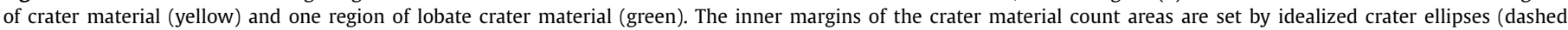

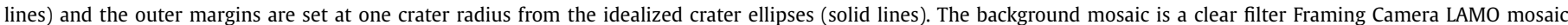

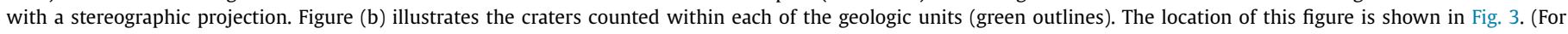
interpretation of the references to color in this figure legend, the reader is referred to the web version of this article.)

Table 1

Table of absolute model ages for a selection of geologic units in the Ezinu quadrangle, derived with the lunar-derived chronology system (columns 2-5) and the asteroid-flux-derived chronology system (columns 6-9) (see Section 2.2 .3 and Hiesinger et al., 2016). The far-left column presents the name of the geologic unit and the areal extent in which craters were counted. The second through fifth and sixth through ninth columns present the derived absolute model age (AMA), the associated statistical error, the number of craters fitted to the crater size-frequency distribution curve, and the diameter range of the craters fitted to the curve for, respectively, the lunar-derived absolute model ages and the asteroid-flux-derived absolute model ages.

\begin{tabular}{|c|c|c|c|c|c|c|c|c|}
\hline $\begin{array}{l}\text { Name } \mathcal{E} \text { size of counted } \\
\text { area }\end{array}$ & $\begin{array}{l}\text { Lunar-derived } \\
\text { AMA \& error }\end{array}$ & $\begin{array}{r}N \_c u m(1) \\
\left(\mathrm{km}^{-2}\right)\end{array}$ & $\begin{array}{c}\text { \# of fitted } \\
\text { craters }\end{array}$ & $\begin{array}{l}\text { Fit range } \\
(\mathrm{km})\end{array}$ & $\begin{array}{l}\text { Asteroid-flux-derived } \\
\text { AMA E' error }\end{array}$ & $\begin{array}{r}N \_c u m(1) \\
\left(\mathrm{km}^{-2}\right)\end{array}$ & $\begin{array}{l}\text { \# of fitted } \\
\text { craters }\end{array}$ & $\begin{array}{l}\text { Fit range } \\
(\mathrm{km})\end{array}$ \\
\hline $\begin{array}{l}\text { Crater floor material } \\
\text { hummocky, crater at } \\
62^{\circ} \mathrm{N}, 253^{\circ} \mathrm{E}(651 \\
\left.\mathrm{km}^{2}\right)\end{array}$ & $10.9 \pm 1.3 \mathrm{Ma}$ & 0.0006 & 66 & $0.22-0.71$ & $7.04 \pm 1.4 \mathrm{Ma}$ & 0.0013 & 25 & $0.28-0.89$ \\
\hline $\begin{array}{l}\text { Crater material, crater } \\
\text { at } 62^{\circ} \mathrm{N}, 253^{\circ} \mathrm{E}(540 \\
\left.\mathrm{km}^{2}\right)\end{array}$ & $14.9 \pm 1 \mathrm{Ma}$ & 0.0009 & 214 & $0.16-0.56$ & $12.8 \pm 2.1 \mathrm{Ma}$ & 0.0024 & 37 & $0.28-0.79$ \\
\hline $\begin{array}{l}\text { Lobate material, Messor } \\
\text { crater ('Messor lobate } \\
\text { flow') }\left(345 \mathrm{~km}^{2}\right)\end{array}$ & $64.5 \pm 2.6 \mathrm{Ma}$ & 0.0038 & 602 & $0.16-1.10$ & $46.8 \pm 4.9 \mathrm{Ma}$ & 0.0089 & 90 & $0.28-1.1$ \\
\hline $\begin{array}{l}\text { Crater material, crater } \\
\text { at } 50^{\circ} \mathrm{N}, 239^{\circ} \text { E }(596 \\
\left.\mathrm{km}^{2}\right)\end{array}$ & $68.6 \pm 2.5 \mathrm{Ma}$ & 0.0040 & 752 & $0.18-1.00$ & $49.6 \pm 4.1 \mathrm{Ma}$ & 0.0094 & 148 & $0.29-0.98$ \\
\hline $\begin{array}{l}\text { Crater floor material } \\
\text { hummocky \& crater } \\
\text { floor material } \\
\text { hummocky dark, } \\
\text { Ninsar crater ( } 794 \\
\mathrm{~km}^{2} \text { ) }\end{array}$ & $136 \pm 9.2 \mathrm{Ma}$ & 0.0079 & 216 & $0.35-2.20$ & $87 \pm 5.9 \mathrm{Ma}$ & 0.0166 & 216 & $0.35-2.20$ \\
\hline $\begin{array}{l}\text { Crater material, Messor } \\
\text { crater }\left(1903 \mathrm{~km}^{2}\right)\end{array}$ & $192 \pm 7.1 \mathrm{Ma}$ & 0.0112 & 734 & $0.35-2.20$ & $96.3 \pm 7.6 \mathrm{Ma}$ & 0.0183 & 159 & $0.56-2.20$ \\
\hline $\begin{array}{l}\text { Crater material \& crater } \\
\text { material bright, } \\
\text { crater at } 23^{\circ} \mathrm{N}, 186^{\circ} \\
\mathrm{E}\left(514 \mathrm{~km}^{2}\right)\end{array}$ & $205 \pm 12 \mathrm{Ma}$ & 0.0120 & 285 & $0.32-2.00$ & $88.1 \pm 17$ Ма & 0.0168 & 28 & $0.63-2.00$ \\
\hline $\begin{array}{l}\text { Crater material, Datan } \\
\text { crater }\left(3929 \mathrm{~km}^{2}\right)\end{array}$ & $213 \pm 9.9 \mathrm{Ma}$ & 0.0124 & 464 & $0.51-2.20$ & $\mathrm{~N} / \mathrm{A}$ & $\mathrm{N} / \mathrm{A}$ & $\mathrm{N} / \mathrm{A}$ & $\mathrm{N} / \mathrm{A}$ \\
\hline $\begin{array}{l}\text { Crater material \& crater } \\
\text { material dark, Ninsar } \\
\text { crater }\left(2818 \mathrm{~km}^{2}\right)\end{array}$ & $378 \pm 33$ Ма & 0.0221 & 132 & $0.79-2.50$ & $129 \pm 3.8 \mathrm{Ma}$ & 0.0246 & 1139 & $0.35-2.50$ \\
\hline $\begin{array}{l}\text { Crater floor material } \\
\text { hummocky, crater at } \\
39^{\circ} \mathrm{N}, 247^{\circ} \text { E }(629 \\
\left.\mathrm{km}^{2}\right)\end{array}$ & $906 \pm 130 \mathrm{Ma}$ & 0.0529 & 43 & $0.92-3.60$ & $242 \pm 24 \mathrm{Ma}$ & 0.0461 & 98 & $0.63-3.50$ \\
\hline $\begin{array}{l}\text { Cratered terrain, Ezinu } \\
\text { crater }\left(3979 \mathrm{~km}^{2}\right)\end{array}$ & $968 \pm 76 \mathrm{Ma}$ & 0.0565 & 162 & $1.10-4.50$ & $257 \pm 13 \mathrm{Ma}$ & 0.0490 & 359 & $0.79-4.50$ \\
\hline $\begin{array}{l}\text { Cratered terrain, Ezinu } \\
\text { quadrangle }(188,624 \\
\left.\mathrm{km}^{2}\right)\end{array}$ & $\begin{array}{l}3380+110 /-310 \\
\text { Мa }\end{array}$ & 0.2536 & 27 & $45-110$ & $4120+250 /-530 \mathrm{Mа}$ & 0.9155 & 27 & $45-110$ \\
\hline
\end{tabular}


Table 2

\begin{tabular}{lll} 
The symbols and RGB colors for each of the geologic units within our map. \\
\hline Unit name & Symbol on map & RGB color on map \\
\hline Cratered terrain & crt & $125-63-0$ \\
Crater material & c & $255-255-51$ \\
Crater material, dark & cd & $240-240-0$ \\
Crater material, bright & cb & $255-255-179$ \\
Crater floor material hummocky & cfh & $217-149-148$ \\
$\quad$ Crater floor material hummocky, dark & cfhd & $183-81-81$ \\
Crater floor material hummocky, bright & cfhb & $234-197-196$ \\
Crater terrace material & ct & $255-206-51$ \\
Crater terrace material, dark & ctd & $242-184-0$ \\
Crater material lobate & cl & $0-154-0$ \\
Lobate material, smooth & ls & $164-222-0$ \\
Lobate material, smooth, dark & lsd & $139-188-0$ \\
Lobate material, knobby & lk & $73-195-134$ \\
Lobate material, knobby, dark & lkd & $45-135-90$ \\
Lobate material, hummocky & lh & $122-152-62$ \\
Talus material & ta & $0-76-0$ \\
\hline
\end{tabular}

features are spaced at distances of $<3 \mathrm{~km}$, we replace them with representative linear features and point features. Occator crater is cut by the boundary between Ezinu and Occator quadrangles (Buczkowski et al., 2018a). In our quadrangle map, we only include the portion of Occator that is within Ezinu quadrangle. A detailed geologic map of the entire Occator crater and its ejecta will be presented in a forthcoming paper (Scully et al., 2018). In Table 2, we list the symbols and RGB colors of each of the geologic units in our geologic map.

\subsection{Description of Map Units}

\subsubsection{Cratered terrain}

This is the dominant unit within the quadrangle and contains many impact craters (Fig. 6a). While the morphologies of the impact craters lie along a continuum, we base their categorization on whether they lie closer to the raised rim end member or to the degraded rim end member: the raised rim category have a more fresh and sharp appearance in comparison to the craters in the degraded rim category, which have a comparatively more rounded appearance. We interpret that impact craters with raised rims have not been as extensively eroded by later impacts and/or infilled by mass-wasting deposits as those craters with degraded rims, and thus that they are relatively younger. This unit has an intermediate albedo (pixel value: $0.05-0.06$ ) and does not superpose any other geologic units. We interpret the dominant geologic process within this unit to be impact cratering. Mass wasting has also occurred throughout the cratered terrain. For example, mass wasting likely contributed to the degraded appearance of some of the impact craters.

Another process that contributed to the formation of the cratered terrain was the formation of Hanami Planum, the $\sim 555 \mathrm{~km}$ wide elevated region that is partly located within Ezinu quadrangle. The majority of Hanami Planum is mapped as cratered terrain. Hanami Planum may have been formed by a region of upwelling subsurface material (Buczkowski et al., 2018a; Ermakov et al., 2017; Scully et al., 2017). Alternatively, Hanami Planum may be high standing because it is located between regions that were eroded by the formation of ancient impact basins (e.g. Marchi et al., 2016).

The cratered terrain is the stratigraphically oldest unit within Ezinu quadrangle. This unit dominates Ceres' surface outside of Ezinu quadrangle, is also the oldest unit in the global geologic map and is interpreted to be the oldest identifiable crust (Mest et al., 2017). The future combination of our basemap with the hyperspectral VIR datasets (Combe et al., 2018b) may allow for additional units to be identified within the cratered terrain. For exam- ple, future investigations may distinguish differences between the cratered terrain on Hanami Planum and the cratered terrain that occurs at lower elevations.

\subsubsection{Crater material, dark, bright}

This unit surrounds large (>10-km-diameter) impact craters with raised rims (Fig. 6b). This unit superposes the cratered terrain and contains fewer impact craters than the cratered terrain; consequently, it has a comparatively smoother texture. Parts of this unit can have a furrowed appearance. An accurate contact is used when there is a distinct break in slope between the crater material and cratered terrain. However, a discrete boundary between the crater material and cratered terrain is not usually visible and so we generally use an approximate contact. We interpret this unit as ejecta deposits, formed by material ejected from the associated impact craters during their formation. Based on the superposition relationships, we interpret this unit to be younger than the cratered terrain. The two sub-units share the same morphological characteristics as the main unit but with different albedos: the crater material has an intermediate albedo (pixel value: $0.05-0.06$ ), the crater material dark has a low albedo (pixel value: 0.01-0.05) and the crater material bright has a high albedo (pixel value: 0.06-0.08). The crater material dark and crater material bright sub-units were likely formed when material with a darker or brighter albedo than average was excavated from the subsurface. These dark/bright subunits have restricted extents, indicating that their source materials also have restricted extents within Ceres' subsurface and/or that they tend to be more deeply buried, and less likely to be excavated, than the intermediate-albedo source material.

\subsubsection{Crater floor material hummocky, dark, bright}

This unit is located within the floors of large $(>10-\mathrm{km}-$ diameter) impact craters with raised rims (Fig. 6c). This unit has an undulating surface, which gives it a hummocky appearance. The unit occurs within impact craters that superpose the cratered terrain and we identify an accurate contact between the hummocky crater floor material and the cratered terrain. We interpret this unit as mass wasting deposits, which infilled portions of the impact craters as material collapsed from the crater walls to the crater floors. Based on the superposition relationships, we interpret that this unit is younger than the cratered terrain. The hummocky crater floor material sub-units have the same morphological characteristics as the main unit but with different albedos: the hummocky crater floor material has an intermediate albedo (pixel value: 0.05-0.06), the hummocky crater floor material dark has a low albedo (pixel value: 0.01-0.05) and the hummocky crater floor material bright has a high albedo (pixel value: $0.06-0.08$ ). The 


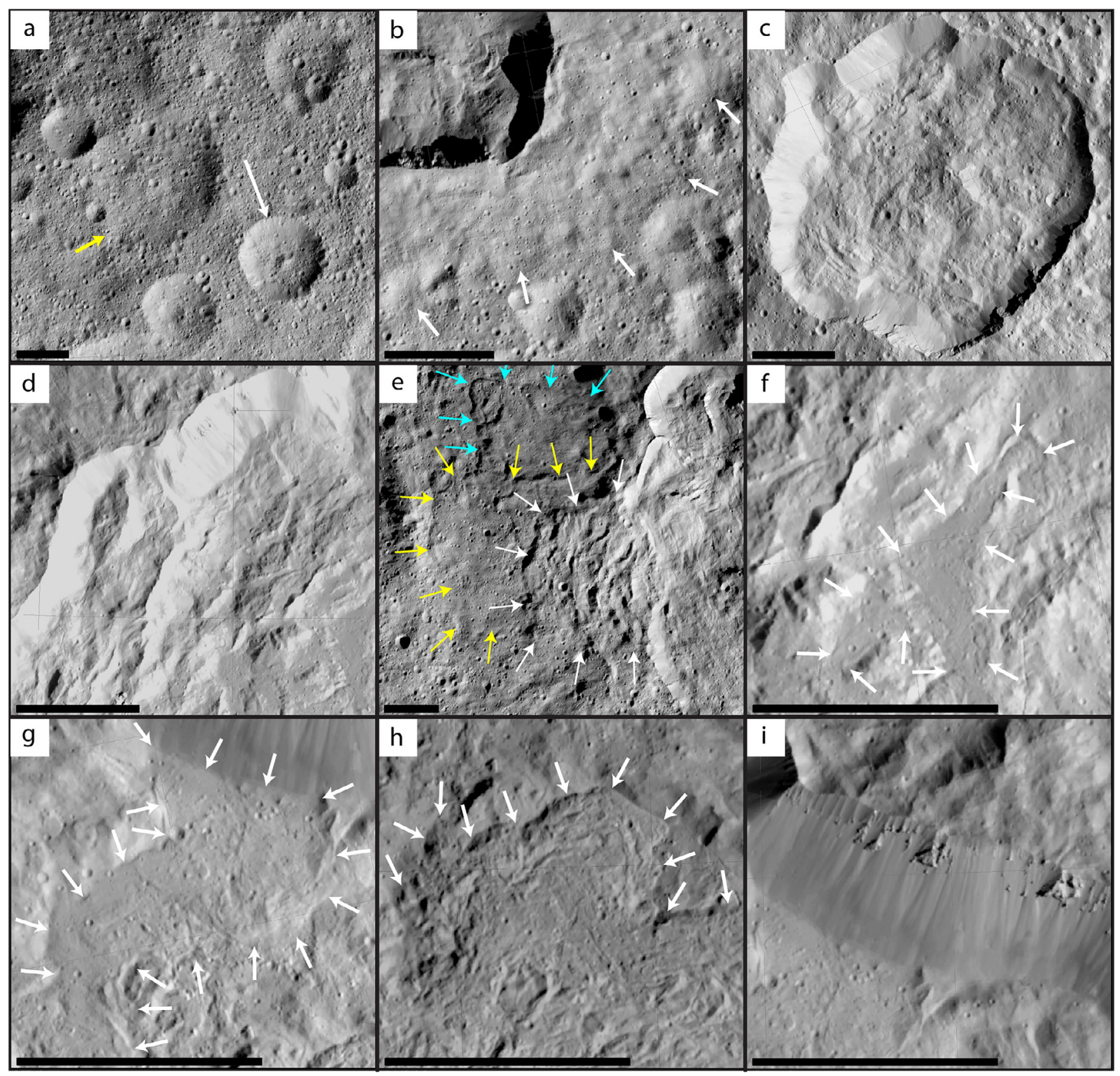

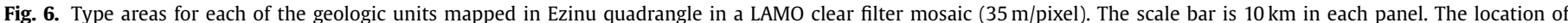

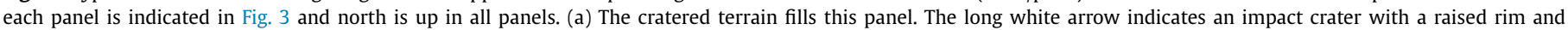

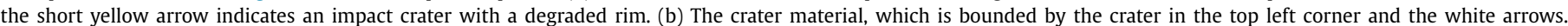

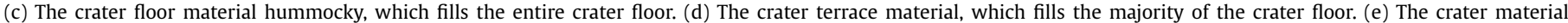

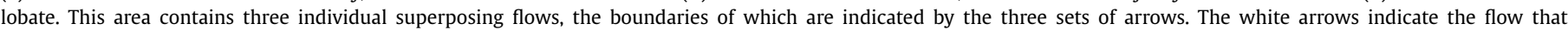

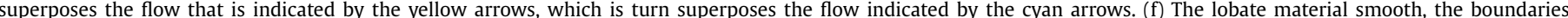

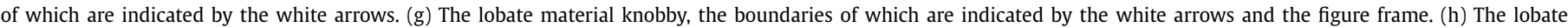
material hummocky, the boundaries of which are indicated by the white arrows and the figure frame. (i) The talus material, which fills the entire crater wall.

hummocky crater floor material dark and crater material dark are located next to each other in Ninsar crater, while the hummocky crater floor material bright and crater material bright are located next to each other in the unnamed crater at $23^{\circ} \mathrm{N}, 186{ }^{\circ} \mathrm{E}$. This suggests that the dark sub-units were sourced from the same area of dark material, which was pre-existing in the Ninsar region before the impact, and that the bright sub-units were sourced from the same area of bright material, which was pre-existing in the 23 ${ }^{\circ} \mathrm{N}-186{ }^{\circ} \mathrm{E}$ region before the impact.

\subsubsection{Crater terrace material, dark}

This unit is located within large (>10-km-diameter) impact craters with raised rims (Fig. 6d). This unit has a stepped appear- ance and the steps are arranged approximately concentrically to the rims of the host impact craters. The unit occurs within impact craters that superpose the cratered terrain and we identify an accurate contact between the crater terrace material and the cratered terrain. We interpret that the unit formed as portions of the crater walls collapsed in a coherent fashion (i.e., as a slump) to form the terraced morphology. Based on the superposition relationships, we interpret that the unit is younger than the cratered terrain. A sub-unit has the same morphological characteristics but a different albedo: the crater terrace material has an intermediate albedo (pixel value: $0.05-0.06$ ), whereas the crater terrace material dark has a low albedo (pixel value: 0.01-0.05). The crater terrace material dark is located next to the crater material dark in Occator 
crater. This suggests that the dark sub-units were sourced from the same area of dark material, which was pre-existing in the Occator region before the impact.

\subsubsection{Crater material lobate}

The unit is located on the outsides of the rims of large ( $>10-\mathrm{km}$-diameter) impact craters with raised rims. This unit has rounded margins in plan view with surficial latitudinal curvilinear furrows (parallel to the crater rims) and longitudinal striations (perpendicular to the crater rims) (Fig. 6e). We map the edges of the lobate crater material as lobate scarps when the margin of the unit forms an area of locally high topography (i.e., a few tens to few hundreds of meters) and there is a distinct break in slope between the unit and the substrate. The unit superposes the crater material, hummocky crater floor material and crater terrace material. We identify accurate contacts between these units and the lobate crater material. We interpret that the lobate crater material flowed out from the rims of the large impact craters onto the underlying materials. The inferred formation mechanism of the lobate crater material is discussed further in Section 4.1.1. Based on superposition relationships, we interpret that this unit was emplaced after the crater material, hummocky crater floor material and crater terrace material.

\subsubsection{Lobate material smooth, smooth dark, knobby, knobby dark, hummocky}

As for the lobate crater material, these units and sub-units have rounded margins in plan view. However, these units and sub-units are only located within Occator crater, do not all originate from the crater rim and have surface textures and albedos that are distinct from one another, upon which we base their names. The lobate material smooth has a smooth surface texture (Fig. 6f), the lobate material knobby has a smooth surface that is interspersed with irregular shaped mounds (Fig. 6g) and the lobate material hummocky has an undulating surface composed of sinuous troughs and ridges that are sometimes concentric to the margins of the unit (Fig. 6h). These units and sub-units superpose the hummocky crater floor material and crater terrace material and we identify accurate contacts between them. Unlike the lobate crater material, none of these units and sub-units originates from the crater rim nor do they appear to have flowed outwards from the rim. Apart from the lobate material knobby dark, which is superposed by talus material (see Section 3.2.7) at the base on the crater wall, these units and sub-units form irregularly shaped deposits on the crater floor, with no obvious point of origin (Fig. 7). The lobate material knobby dark is located next to the crater terrace material dark and crater material dark in Occator crater. This suggests that the dark sub-units were sourced from the same area of dark material, which was pre-existing in the Occator region before the impact. Our favored interpretation of these units and sub-units is that they are impact melt deposits that formed during the formation of Occator crater. A detailed analysis of the formation and evolution of Occator crater is beyond the scope of this study. Further analysis is presented in Buczkowski et al. (2018b), Neesemann et al. (2018), and Scully et al. (2018).

\subsubsection{Talus material}

This unit is located within large ( $>10-\mathrm{km}$-diameter) impact craters with raised rims (Fig. 6i). One side of the unit is always located along the interiors of the crater rims. The unit occupies the upper to lower portions of the crater walls. The unit has a smooth surface texture, contains individual lobes of material and has an intermediate albedo (pixel value: $0.05-0.06$ ). The unit superposes the crater terrace material, the hummocky crater floor material and the lobate material knobby dark. We identify accurate contacts between these units and the talus material. We interpret this unit as a mass-wasting deposit, which formed as material was transported from the crater rims down the crater walls. Seismic shaking from the formation of nearby, younger impact craters probably triggered the mass wasting. Based on superposition relationships, we interpret that this is the youngest unit within Ezinu quadrangle.

\section{Discussion}

\subsection{Insights derived from geologic mapping}

\subsubsection{Lobate flows}

The lobate crater material geologic unit (see Section 3.2.5) is comprised of four distinct lobate flows outside Datan crater and inside Messor crater. The three Datan lobate flows appear to have been emplaced by flowing out of Datan onto the surrounding crater material, indicating that the crater material was emplaced first (Fig. 8). We interpret the crater material as ballistically emplaced ejecta that formed during the Datan-crater-forming impact (see Section 3.2.2). Datan lobate flows \#1-3 are on average $\sim 23 \mathrm{~km}$ in length, $\sim 28 \mathrm{~km}$ in width and, using the shape model, we find that their lobate scarp margins are a maximum of $\sim 500 \mathrm{~m}$ thick. Superposition relationships indicate that flow \#3 formed first, followed by flow \#2 and flow \#1. The lobate flows and the ballistically deposited ejecta both originate from the rim of Datan crater, suggesting that the lobate flows may be a type of impact-crater ejecta. The Datan lobate flows are only observed on the western side of Datan.

The fourth lobate flow, which we term the Messor lobate flow, originates at the rim of an unnamed crater at $50{ }^{\circ} \mathrm{N}, 239^{\circ} \mathrm{E}$. This unnamed crater cross-cuts the eastern rim of Messor crater and the Messor lobate flow appears to have been emplaced by flowing out onto the hummocky crater floor material within Messor (Fig. 9). The Messor lobate flow is $\sim 20 \mathrm{~km}$ long, $\sim 12 \mathrm{~km}$ wide and its lobate scarp margin is a maximum of $\sim 100 \mathrm{~m}$ thick. The absolute model ages of the Messor lobate flow are $\sim 65 \mathrm{Ma}^{\mathrm{L}}$ or $\sim 47$ $\mathrm{Ma}^{\mathrm{A}}$ (Table 1). Crater material originates from the rim of the unnamed crater and we interpret it as ballistically emplaced ejecta (Fig. 9). The absolute model ages of this ballistically emplaced ejecta and the Messor lobate flow are almost identical, at $~ 69$ $\mathrm{Ma}^{\mathrm{L}}$ or $\sim 50 \mathrm{Ma}^{\mathrm{A}}$, and $\sim 65 \mathrm{Ma}^{\mathrm{L}}$ or $\sim 47 \mathrm{Ma}^{\mathrm{A}}$, respectively (Table 1 ). Therefore, similarly to the Datan lobate flows, we interpret that the Messor lobate flow is also a manifestation of impact-crater ejecta that originated from the unnamed crater. The Messor lobate flow only occurs on the western side of the unnamed source crater.

The surfaces of the lobate flows are covered by curvilinear furrows and striations (Fig. 8) and they are morphologically distinct from mass-wasting deposits observed on Vesta (Scully et al., 2015; Krohn et al., 2014). Schmidt et al. (2017) and Buczkowski et al. (2016) concluded that the morphological characteristics (i.e., lobate flow fronts, latitudinal curvilinear furrows and longitudinal striations) of these and other lobate flows on Ceres are analogous to fluidized ejecta blankets on Mars and Ganymede, where the entrainment of ice is thought to give fluidized ejecta blankets their distinctive morphology (e.g. Boyce et al., 2010; Senft and Stewart, 2008). The superposition of the lobate flows on top of the ballistically emplaced ejecta is similar to the emplacement sequence proposed by Osinski et al. (2011) for a range of inner Solar System bodies, where ballistically emplaced ejecta is superposed by melt flows that move out of the transient cavity by uplift during the modification stage of the crater's formation. Therefore, we propose the following formation sequence for the lobate flows in the Ezinu quadrangle: (1) the crater-forming impacts deposit the ballistically emplaced ejecta and heat/melt water-ice-rich material sourced from depth; (2) this melted water-ice-rich material flows out of the craters' cavities during the modification stage to superpose the ballistically emplaced ejecta; and then (3) the 


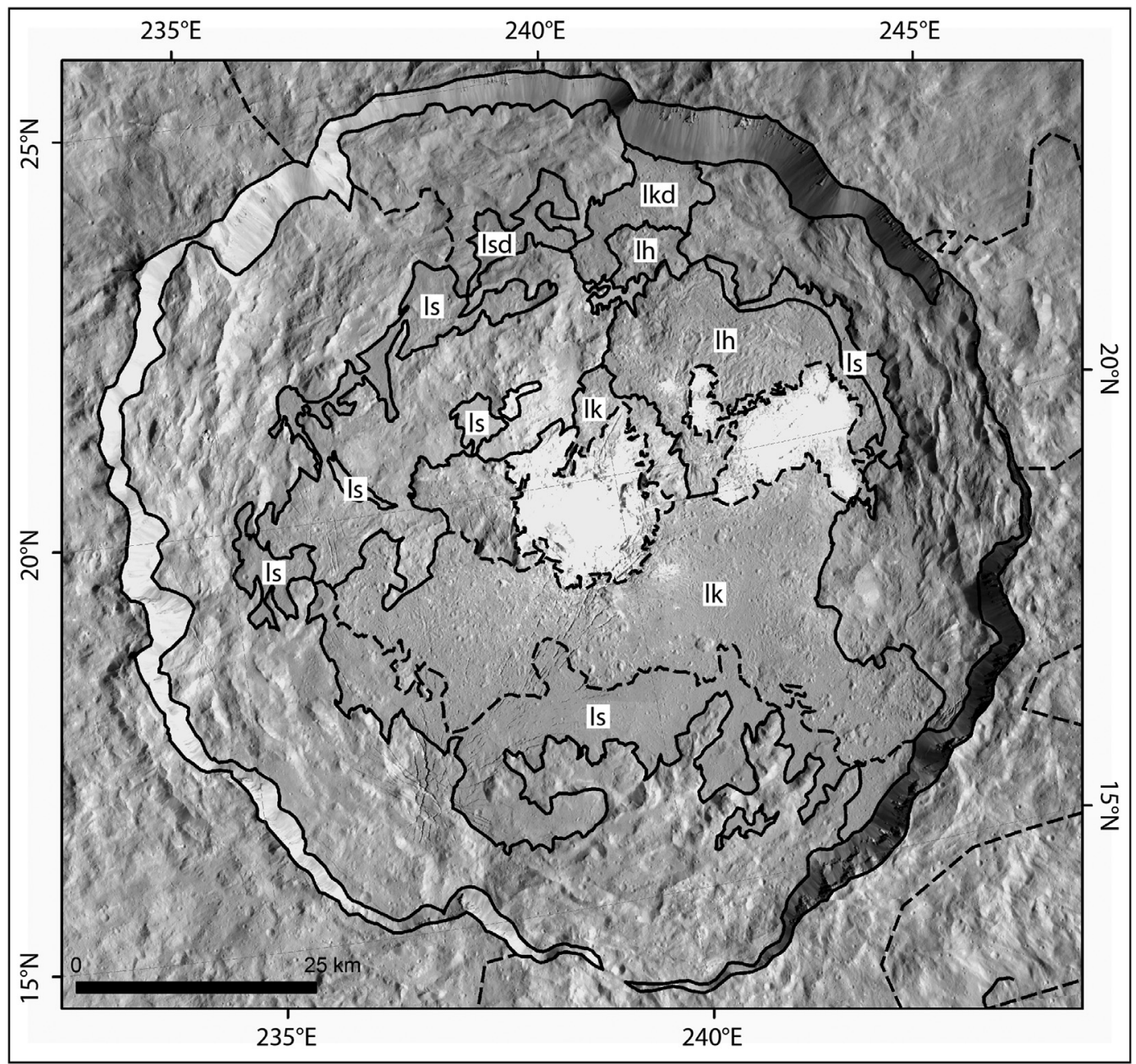

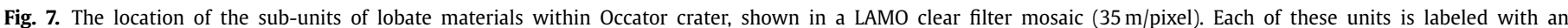

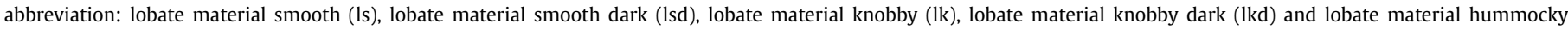

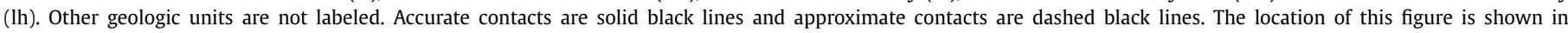
Fig. 3.

lobate flows may continue to flow to a limited extent until all of the impact-induced heat is dissipated. We interpret that the lobate flows are only located on one side of their source craters, and are only found in association with a couple of impact craters, because the water-ice-rich source material has restricted extents within Ceres' subsurface and/or may be so deeply buried that it is rarely excavated by impacts. In addition, there is a pre-existing depression on the western side of Datan, and Messor formed a preexisting depression on the western side of the unnamed source crater (Fig. 3). It would be easier for the lobate flows to flow in the direction of these pre-existing depressions than to flow in other directions.

\subsubsection{Bright spots}

We define a bright spot as a region that is $<5 \mathrm{~km}$ in size and has a distinctly high albedo (pixel value $>0.06$ ) in photometrically corrected data. We map 134 bright spots, which generally occur on the ejecta, rims and interiors of small impact craters (i.e., a few kilometers in diameter or less) that have a fresh appearance. For example, a prominent cluster of bright spots is located within Geshtin crater and these bright spots are associated with $<1 \mathrm{~km}$ diameter impact craters (Fig. 10). We interpret the bright-spotforming materials to have been excavated from Ceres' subsurface during the formation of the small impact craters, which results in the small impact craters having bright ejecta blankets and interiors. Using the depth-to-diameter ratio for simple craters on Ceres ( 0.2; Hiesinger et al., 2016), we find that impact craters of this size (a few kilometers in diameter) likely excavated material from up to $\sim 500 \mathrm{~m}$ within Ceres' subsurface. We propose that this excavation occurred in the geologically recent past, and that the bright spots and their host small impact craters are some of the youngest features in the quadrangle, because bright spots are interpreted to darken over time by mixing with other materials on Ceres' surface (Palomba et al., 2018).

There are many small impact craters that do not have bright ejecta blankets and interiors, which indicates that the bright-spotforming materials are spatially restricted within Ceres' subsurface. Stein et al. (2018) propose that bright-spot-forming materials are formed as brine precipitates in impact craters, broadly similar to the faculae in Occator crater (De Sanctis et al., 2016), and are then buried and mixed into the subsurface until they are excavated by impacts and mass wasting. Thus, it is likely that some of the bright spots in Ezinu quadrangle are excavated brine precipitates. The latitude $\left(\sim 21-66^{\circ} \mathrm{N}\right)$ and geologic location (ejecta, rims and interiors of small impact craters) of the bright spots in Ezinu quadrangle are analogous to bright spots found in mass wasting deposits within 


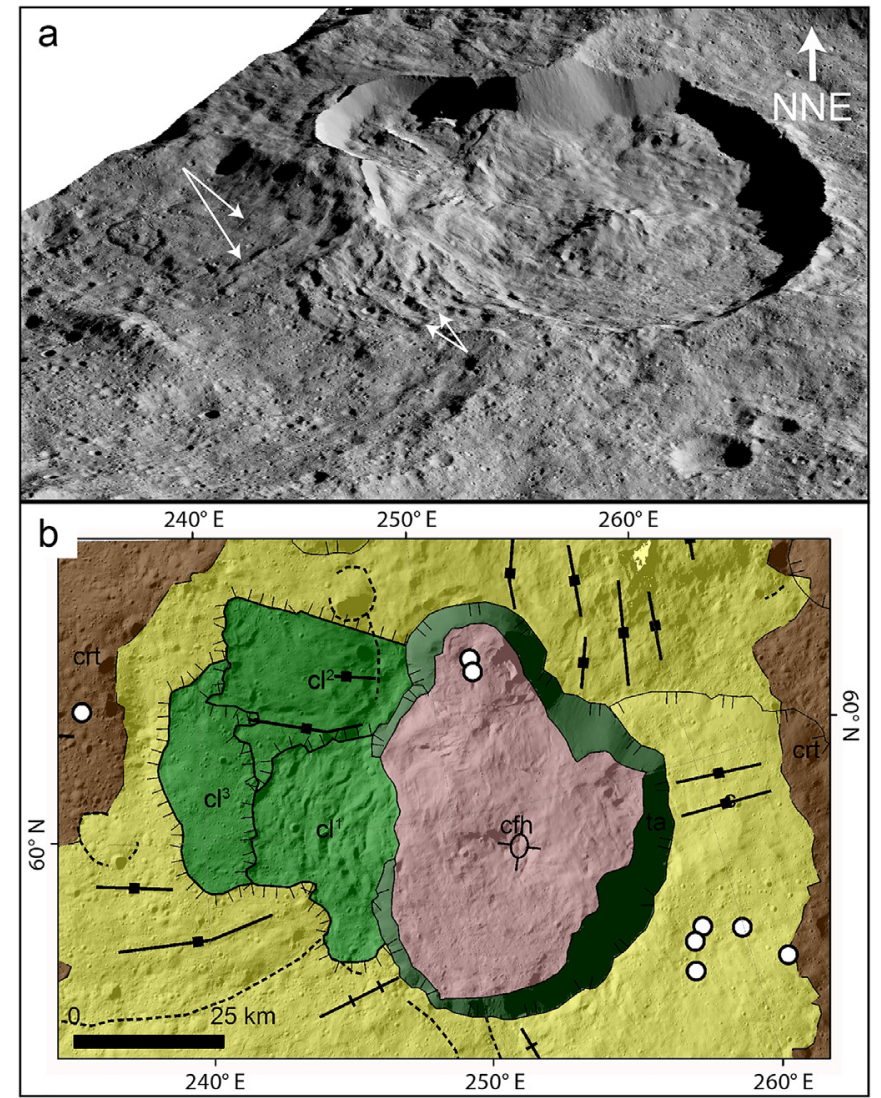

Fig. 8. (a) Perspective view of the three lobate flows and the crater material that originate from Datan crater. Short white arrows indicate the latitudinal curvilinear furrows (parallel to the crater rim) and long white arrows indicate the longitudinal striations (perpendicular to the crater rim). (b) Geologic map, which illustrates the locations of the three lobate flows $\left(\mathrm{cl}^{1}, \mathrm{cl}^{2}\right.$ and $\mathrm{cl}^{3}$, shown in green) and the crater material (yellow). The map symbols are the same as those defined in the legend of Fig. 4. The location of this figure is shown in Fig. 3. (For interpretation of the references to color in this figure legend, the reader is referred to the web version of this article.)

Oxo crater $\left(42.2^{\circ} \mathrm{N}, 359.6^{\circ} \mathrm{E}\right)$ in the neighboring Fejokoo quadrangle. These bright regions are interpreted as water ice (Combe et al., 2016; Hughson et al., 2018). Thus, we suggest that as further hyperspectral VIR data are analysed for the upcoming special issue about the compositional mapping of Ceres (Combe et al., 2018b), some of the bright spots within Ezinu quadrangle may also come to be identified as regions of water ice excavated by small impact craters.

\subsubsection{Linear features}

We divide linear features within Ezinu quadrangle into two groups: those that are outside of impact craters, which tend to be $\geq 2 \mathrm{~km}$ wide, and those that are within the floors/ejecta of impact craters, which tend to be $<2 \mathrm{~km}$ wide (Fig. 11). The linear features outside of impact craters consist of chains of near-circular depressions, which have clearly defined rims and are often arranged in radial patterns around a central impact crater, e.g. Occator and Datan craters (Figs. 11 and 12a). These characteristics are indicative of formation by an impact, and thus we term these features impact crater chains. The impact crater chains frequently transition into linear depressions, suggesting they have a common formation mechanism (Fig. 12a). We term these linear depressions 'furrows'. We interpret the impact crater chains and furrows as secondary crater chains that formed as material ejected during the formation of a source impact crater impacted, bounced across and scoured the surrounding surface.

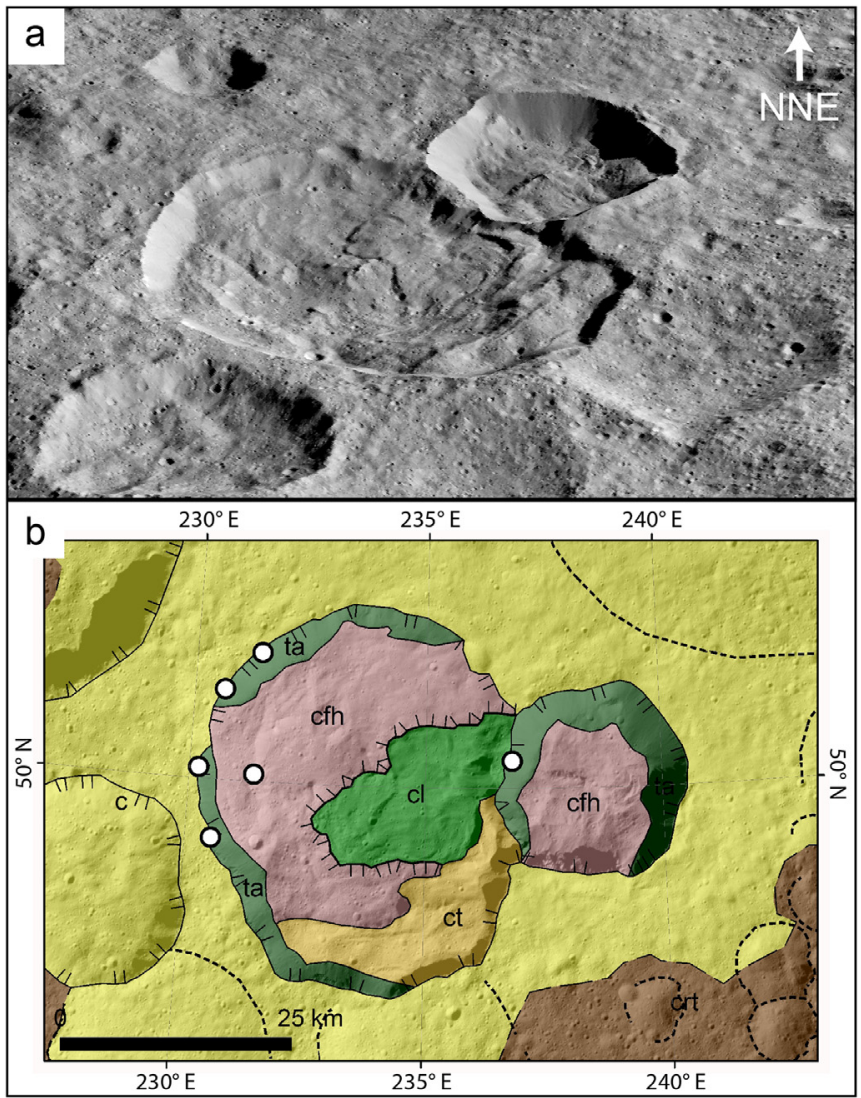

Fig. 9. (a) Perspective view of the lobate flow within Messor crater, which originates from the unnamed crater to Messor's east. (b) Geologic map, which illustrates the locations of the lobate flow (green) and the crater material (yellow). The map symbols are the same as those defined in the legend of Fig. 4. The location of this figure is shown in Fig. 3. (For interpretation of the references to color in this figure legend, the reader is referred to the web version of this article.)

The Junina Catenae are a specific set of linear features that are partially located within Ezinu quadrangle $\left(\sim 12-46^{\circ} \mathrm{N}, \sim 95-\right.$ $265^{\circ} \mathrm{E}$ ) and display all of the morphological characteristics of secondary crater chains described above (Figs. 11 and 12a and b). However, they are not radially arranged around a crater. Scully et al. (2017) and Schmedemann et al. (2017) interpreted the Junina Catenae were formed by the impact of material that was ejected at velocities of $\sim 390-520 \mathrm{~m} / \mathrm{s}$ from Urvara and Yalode impact craters. Urvara is located at $46^{\circ} \mathrm{S}, 249^{\circ} \mathrm{E}$ and Yalode is situated at $43^{\circ} \mathrm{S}, 292^{\circ} \mathrm{E}, \sim 800 \mathrm{~km}$ and $\sim 1000 \mathrm{~km}$, respectively, from the approximate center of the Junina Catenae (at $\sim 29^{\circ} \mathrm{N}, \sim 180^{\circ}$ E). On account of Ceres' low gravity $\left(0.27 \mathrm{~m} / \mathrm{s}^{2}\right)$, ejecta distribution modeling predicts that material ejected at such velocities $(\sim 390$ $520 \mathrm{~m} / \mathrm{s}$ ) will travel ballistically above Ceres' surface for $\sim 6-8$ hours. Ceres fully rotates in $\sim 9 \mathrm{~h}$. Thus, by the time the lofted material returns to the surface, it is far from its source craters. Predictions of the impact location and pattern of this material match the mapped location of the Junina Catenae. Further details can be found in Scully et al. (2017) and Schmedemann et al. (2017). The Junina Catenae are superposed by the ejecta from, and crosscut by secondary crater chains radial to, Occator crater (Fig. 12b). Consequently, we interpret that the Junina Catenae formed before Occator. This is consistent with the origination of the Junina Catenae-forming material from Urvara and Yalode craters, which Mest et al. (2017) interpret to pre-date Occator.

The linear features within the floors/ejecta of impact craters mainly consist of linear depressions, which we term grooves. The grooves display S-shaped linkages and/or en-echelon patterns in 


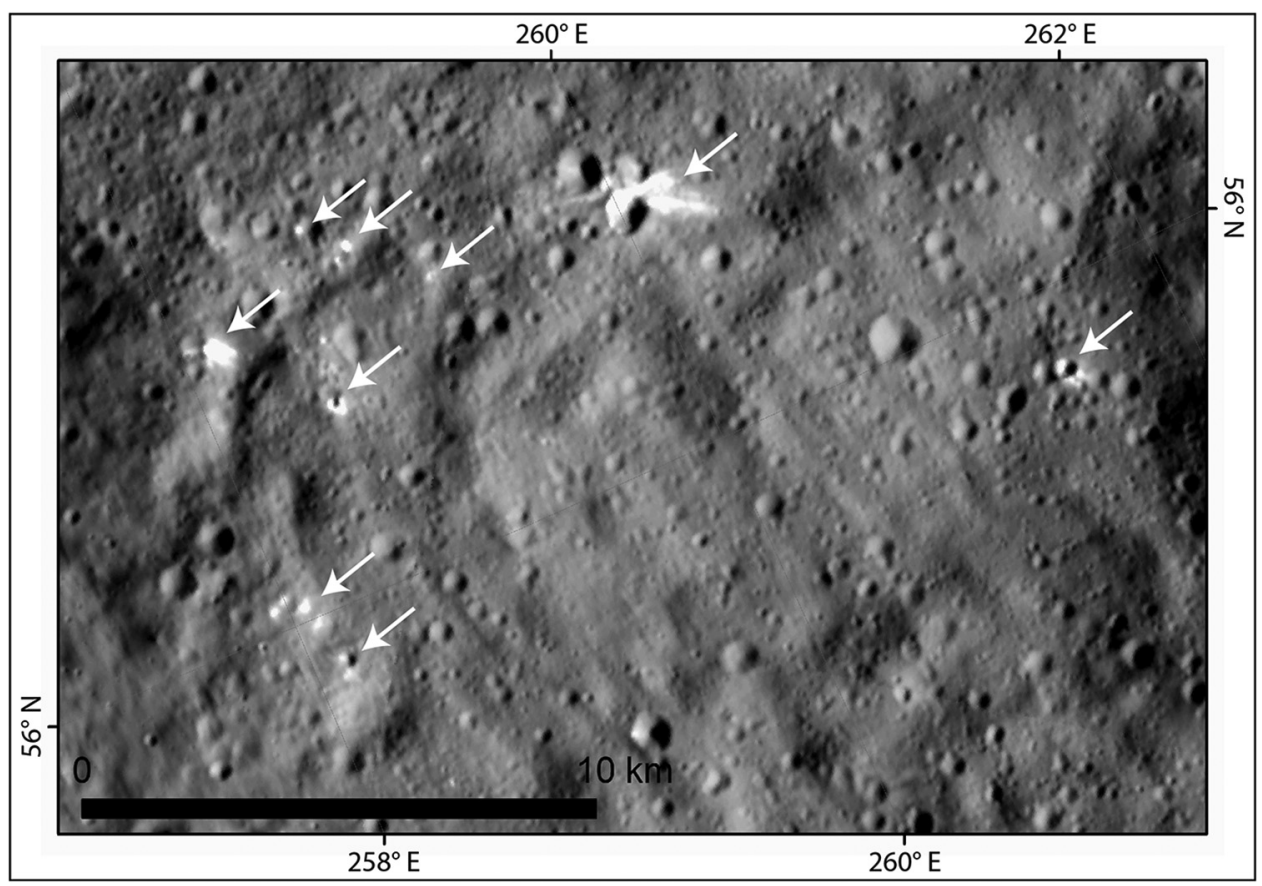

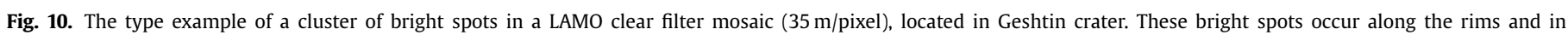
the interiors, and are interpreted as the ejecta, of impact craters that are $<1 \mathrm{~km}$ in diameter. The location of this figure is shown in Fig. 3 .

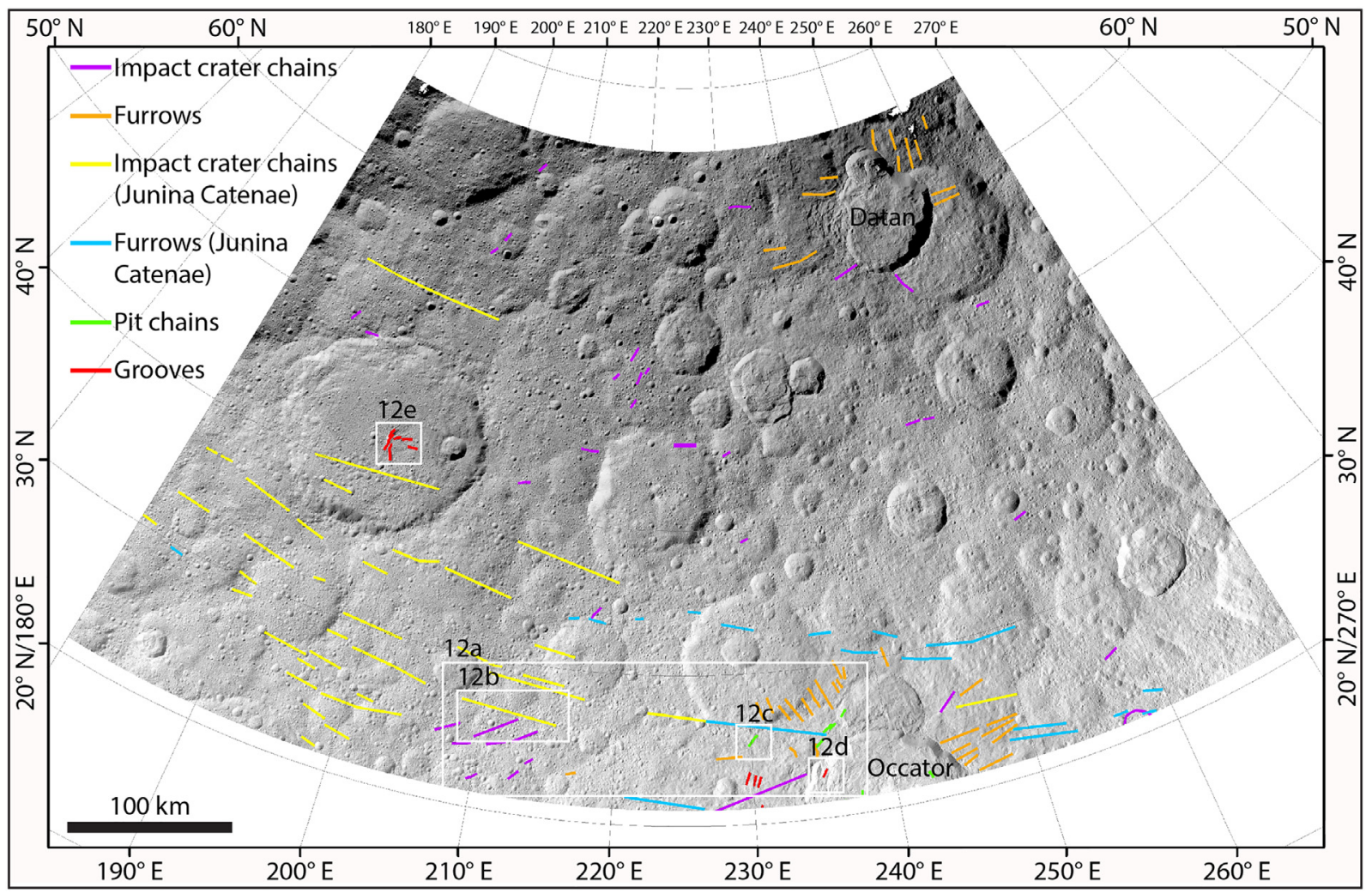

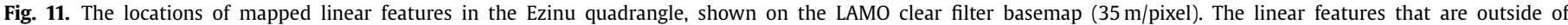

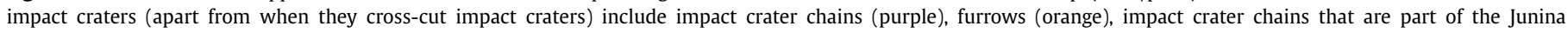

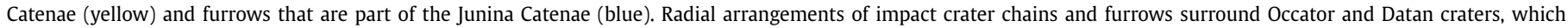

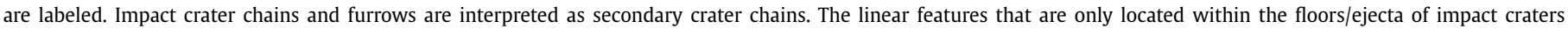

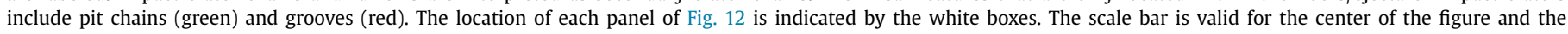

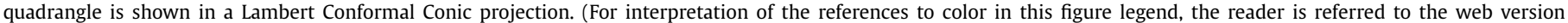
of this article.) 


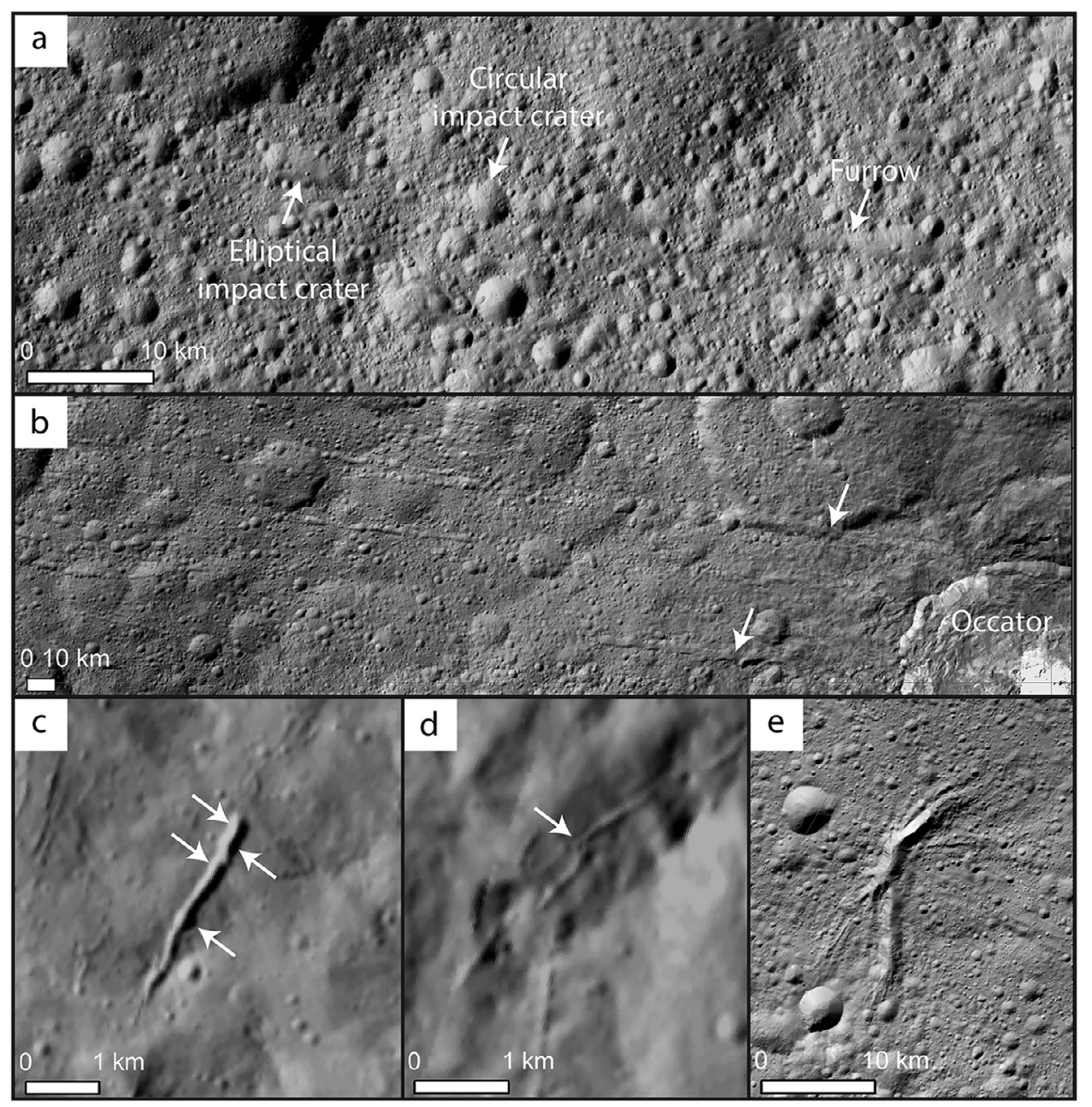

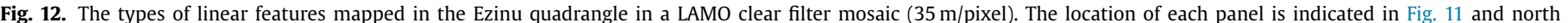

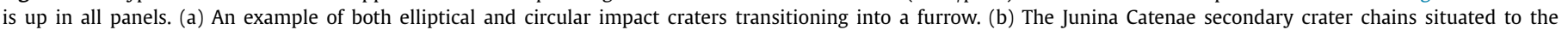

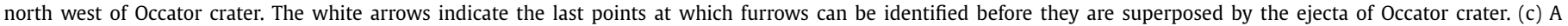

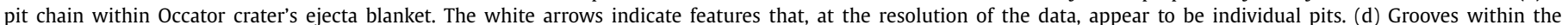
floor of Occator crater. The white arrow highlights an apparent S-shaped pattern. (e) Grooves within the floor of Ezinu crater.

plan view, where individual segments trend in the same direction and are broadly aligned to one another (Fig. 12d). The grooves sometimes appear to transition into chains of near-circular depressions, which have more irregular shapes and appear to coalesce together more than the impact crater chains. These morphological characteristics are comparable to pit chains identified on various bodies, which generally form by collapse/draining of surficial material into subsurface voids formed by dilational faulting/extension fractures (e.g. Scully et al., 2014; Ferrill et al., 2011; Buczkowski et al., 2008; Wyrick et al., 2004). Thus, we interpret these nearcircular depressions to be pit chains. It is likely that as chains grow and merge, they form the grooves (e.g. Buczkowski et al., 2016; Wyrick et al., 2004; Sims et al., 2003). Further discussion is presented in a publication about of all the linear features on Ceres' surface (Scully et al., 2017).

In Ezinu quadrangle, we identify pit chains and grooves, which are generally $<2 \mathrm{~km}$ in width, within the floors of Occator and Ezinu craters (Fig. 12c-e). However, the definitive recognition of these features is often limited by the resolution of the data ( $\geq 35 \mathrm{~m} /$ pixel) (Fig. 12c). Previous studies suggested that these linear features overlie subsurface fractures (Scully et al., 2017; Buczkowski et al., 2016). Buczkowski et al. (2018b) interpret that such fractures form by localized cryomagmatic uplift underneath the crater floors, because the pit chains and grooves and their host craters are morphologically analogous to lunar floor-fractured craters thought to overlie inflated magma reservoirs (Jozwiak et al., 2015; Schultz, 1976). We also identify pit chains and grooves within the ejecta blanket of Occator crater (Fig. 12c), which Buczkowski et al. (2018b) regard as having formed by differential compaction of volatile-rich ejecta over localized regions of preexisting topography.

\subsubsection{Central peaks and central pits}

We identify central peaks within ten large (i.e., $>10-\mathrm{km}$ diameter) impact craters in the quadrangle, and we map these central peaks as point features (Fig. 13). Central peaks are topographic rises that occur at or near the centers of the impact craters. We identified central peaks using profiles derived from the shape model. One crater that contains a central peak, Kaikara crater, also contains a central pit that is $\sim 900 \mathrm{~m}$ deep, $\sim 5 \mathrm{~km}$ in diameter and adjacent to the central peak (Fig. 13). The $>10 \mathrm{~km}$ diameters of the ten host craters are within the diameter range of complex craters on Ceres (Hiesinger et al., 2016). Central peaks and central pits occur within complex craters throughout the Solar System and are a typical structural outcome of the impact process. Central pits are particularly common in impact craters that formed on icy bodies, such as Ganymede and Callisto, or on bodies that contain ice, such as Mars (e.g. Melosh, 2011). Hiesinger et al. (2016) interpret the 


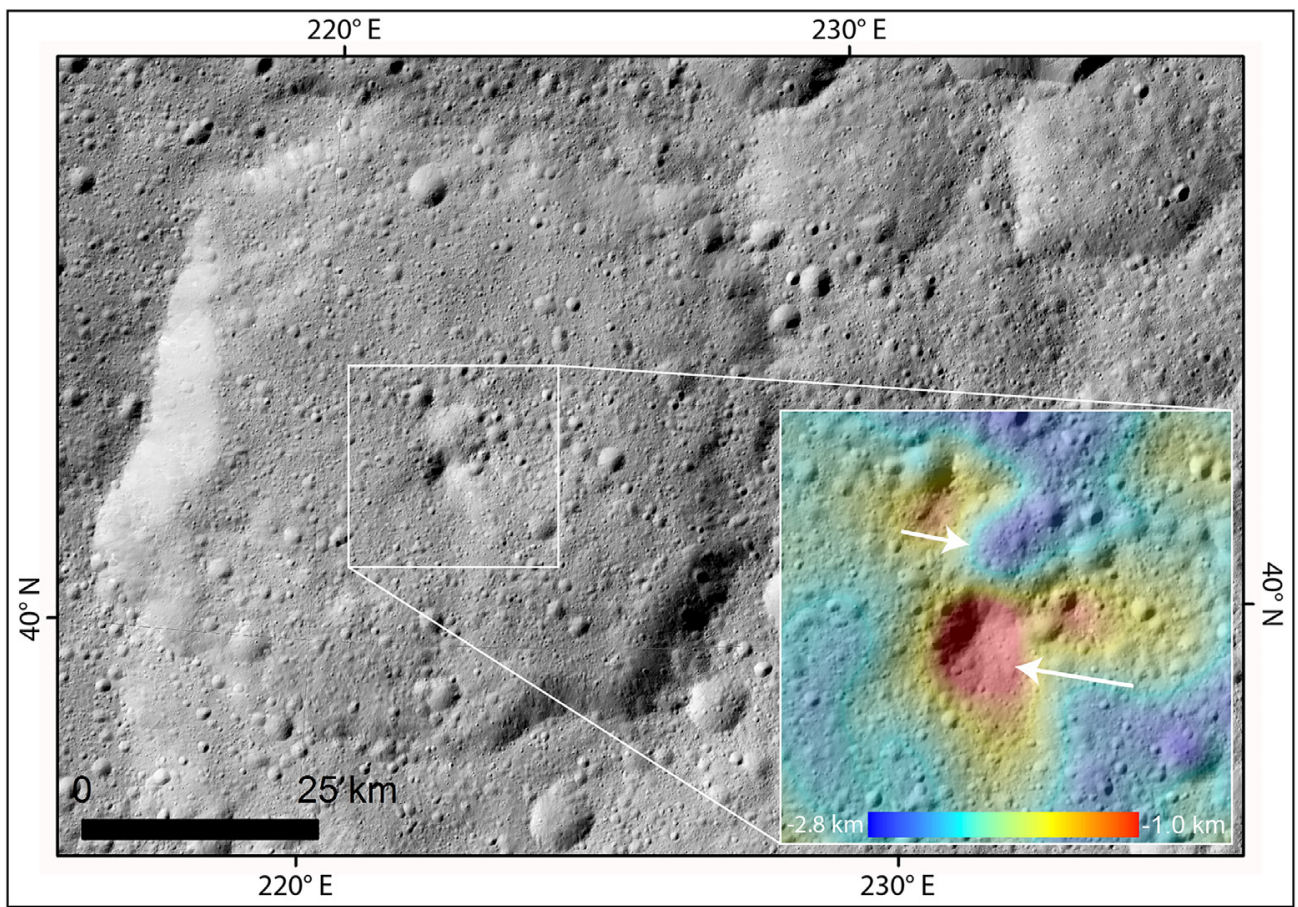

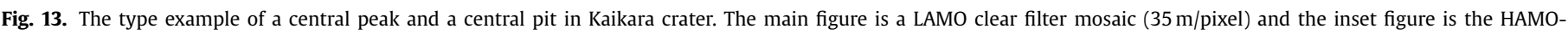

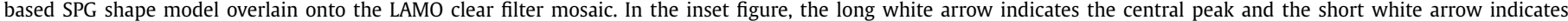
the central pit. The location of the main figure is shown in Fig. 3.

presence of central pit craters to indicate that the Cerean target material is weaker than the crystalline rock found on bodies such as Vesta or the Moon, and that some ice must be present in Ceres' subsurface.

\subsection{Geologic history of Ezinu quadrangle and correlation of map units}

\subsubsection{Stratigraphically oldest period}

We find that the cratered terrain does not superpose any other geologic units (see Section 3.2.1). Therefore, we regard it as the stratigraphically oldest geologic unit within the Ezinu quadrangle and thus it defines the stratigraphically oldest period preserved here. This interpretation is supported by the absolute model ages of the cratered terrain, which are the oldest identified in the quadrangle: $\sim 3380 \mathrm{Ma}^{\mathrm{L}}$ or $\sim 4120 \mathrm{Ma}^{\mathrm{A}}$ (Fig. 14 and Table 1). These model ages are in keeping with the range of ages derived for the cratered terrain across Ceres (Mest et al., 2017). Along with impact cratering, mass wasting occurred throughout the cratered terrain. A key event during the stratigraphically oldest period is the formation of the high standing Hanami Planum, which occupies a large portion of the southern half of Ezinu quadrangle. A region of upwelling subsurface material may have formed Hanami Planum (Buczkowski et al., 2018a; Ermakov et al., 2017; Scully et al., 2017) or it may be a region that was not eroded by the formation of ancient impact basins (e.g. Marchi et al., 2016) (see Section 3.2.1).

Craters that we interpret to have formed during the stratigraphically oldest period, such as Ezinu and Kaikara, do not have ejecta or interior deposits that are distinguishable from the surrounding cratered terrain. The cratered terrain within Ezinu crater has a model age of $\sim 968 \mathrm{Ma}^{\mathrm{L}}$ or $\sim 257 \mathrm{Ma}^{\mathrm{A}}$ (Table 1). We conclude that Geshtin crater also formed during the stratigraphically oldest period, because much of its interior is superposed by ejecta from Datan crater, which likely formed during the stratigraphically intermediate period (see Section 4.2.2). The Junina Catenae also formed during the stratigraphically oldest period, because they are superposed by the ejecta, and cross-cut by secondary crater chains, from the stratigraphically-intermediate Occator crater (see Sections 4.1 .3 and 4.2.2).

\subsubsection{Stratigraphically intermediate period}

The formation of impact craters such as Ninsar, Datan, Messor and Occator formed geomorphologically distinct geologic units that superpose the cratered terrain and define the stratigraphically intermediate period: crater materials (i.e. ejecta), hummocky crater floor materials and crater terrace materials (Fig. 14). Using the absolute model ages of the crater's ejecta to approximate their formation ages we find that Ninsar is $\sim 378 \mathrm{Ma}^{\mathrm{L}}$ or $\sim 129 \mathrm{Ma}^{\mathrm{A}}$, Datan is $\sim 213 \mathrm{Ma}^{\mathrm{L}}$ and $\mathrm{N} / \mathrm{A}^{\mathrm{A}}$, the unnamed bright crater at $23^{\circ} \mathrm{N}, 186^{\circ} \mathrm{E}$ is $\sim 205 \mathrm{Ma}^{\mathrm{L}}$ or $\sim 88 \mathrm{Ma}^{\mathrm{A}}$, Messor is $\sim 192 \mathrm{Ma}^{\mathrm{L}}$ or $\sim 96 \mathrm{Ma}^{\mathrm{A}}$ and the unnamed crater at $62^{\circ} \mathrm{N}, 253^{\circ} \mathrm{E}$ is $\sim 15 \mathrm{Ma}^{\mathrm{L}}$ or $\sim 13 \mathrm{Ma}^{\mathrm{A}}$ (Table 1). We do not determine an asteroid-flux-derived absolute model age for the ejecta of Datan crater because the crater size distribution function of the ejecta is too steep to fit to the curve of the asteroid-flux-derived chronology system. We postulate that this steepness is due to the presence of a relatively large amount of secondary craters, sourced from Datan crater during its formation. However, these postulated secondary craters do not form recognizable clusters or chains that would allow us to exclude them from our count area. Published model ages of Occator indicate that this crater formed at $\sim 34 \mathrm{Ma}^{\mathrm{L}}$ (Nathues et al., 2017) and model ages that will be presented in a future publication indicate that it formed at $\sim 20 \mathrm{Ma}^{\mathrm{L}}$ (Neesemann et al., 2018). By definition, the radial secondary crater chains surrounding Datan and Occator formed contemporaneously with these craters.

We interpret the lobate crater material as water-ice-rich melt flows that were emplaced after the deposition of the ballistically emplaced ejecta (crater material) (see Section 4.1.1). Similarly, we interpret the units and sub-units of lobate materials found exclusively within Occator crater as impact melt (see Section 3.2.6). Thus, under our proposed scenario, the formation of the lobate crater material/lobate materials and the formation of the crater 


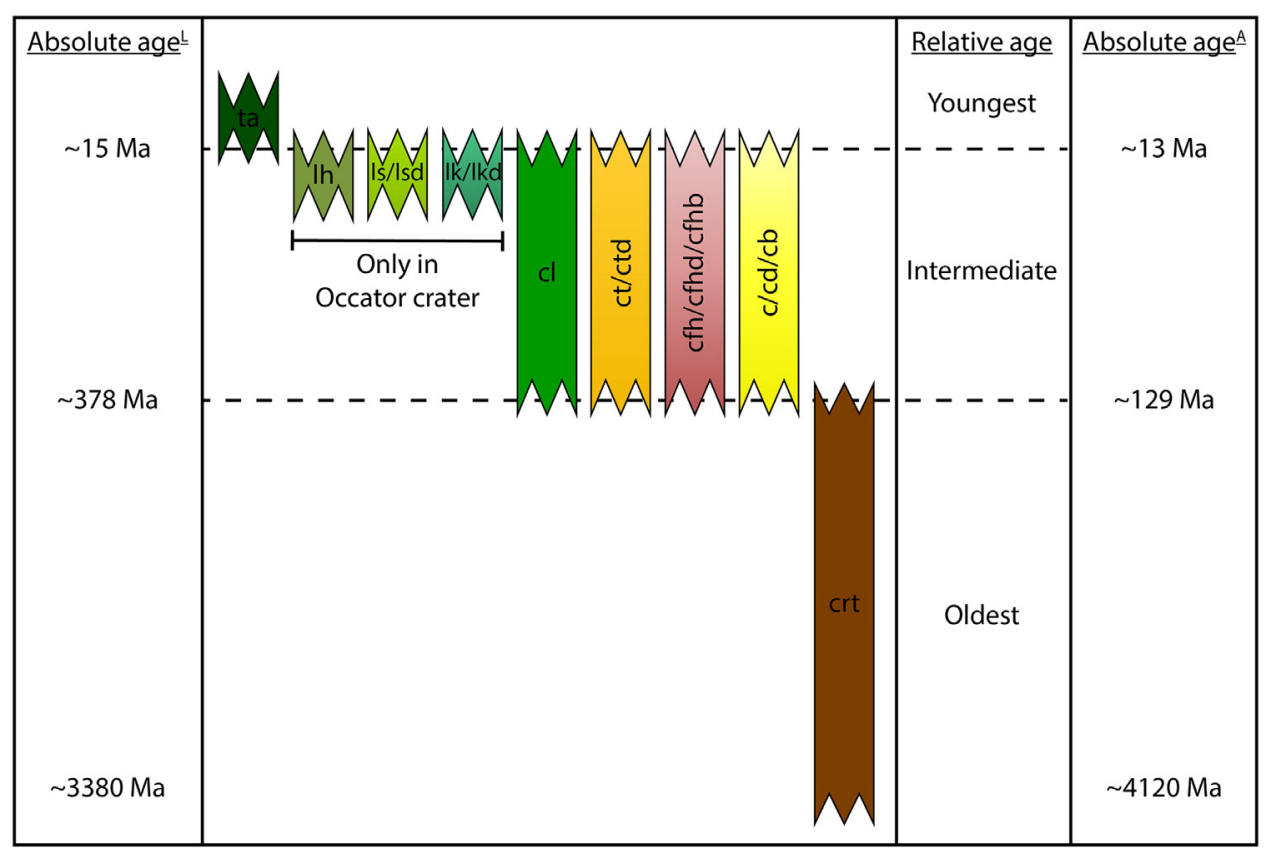

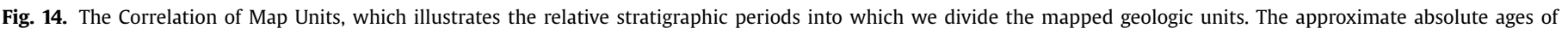

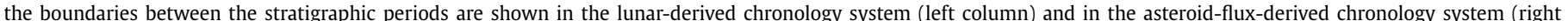

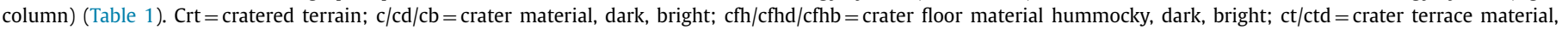
dark; $\mathrm{cl}=$ crater material lobate; lk/lkd= lobate material knobby, dark; ls/lsd=lobate material smooth, dark; lh=lobate material hummocky; ta = talus material.

material, hummocky crater floor material and crater terrace material were all driven by the creation of their source impact craters. Consequently, although the lobate crater material/lobate materials superpose the crater material, hummocky crater floor material and crater terrace material, this superposition must have occurred geologically instantaneously, shortly after the formation of their host craters. This interpretation is consistent with the model ages of the crater material (ballistic ejecta) and lobate crater material (water-ice-rich melt flow) that originate from the crater at $50^{\circ} \mathrm{N}, 239^{\circ} \mathrm{E}$, which are essentially identical when the unquantifiable intrinsic errors of both chronology systems are taken into account: $\sim 69 \mathrm{Ma}^{\mathrm{L}}$ versus $\sim 65 \mathrm{Ma}^{\mathrm{L}}$ and $\sim 50 \mathrm{Ma}^{\mathrm{A}}$ versus $\sim 47 \mathrm{Ma}^{\mathrm{A}}$ (see Section 4.1.1 and Table 1). Consequently, we also place the lobate crater material and the units and sub-units of lobate materials into the stratigraphically intermediate period.

The hummocky crater floor materials in Ninsar crater and in the unnamed crater at $62^{\circ} \mathrm{N}, 253^{\circ} \mathrm{E}$ have younger absolute model ages than the ejecta: $\sim 136 \mathrm{Ma}^{\mathrm{L}}$ versus $\sim 378 \mathrm{Ma}^{\mathrm{L}}$ or $\sim 87 \mathrm{Ma}^{\mathrm{A}}$ versus $\sim 129 \mathrm{Ma}^{\mathrm{A}}$ for Ninsar and $\sim 15 \mathrm{Ma}^{\mathrm{L}}$ or $\sim 13 \mathrm{Ma}^{\mathrm{A}}$ and $\sim 11 \mathrm{Ma}^{\mathrm{L}}$ or $\sim 7 \mathrm{Ma}^{\mathrm{A}}$ for the unnamed crater at $62^{\circ} \mathrm{N}, 253^{\circ} \mathrm{E}$ (Table 1 ). Similar age discrepancies have been noted for lunar craters. For example, older absolute model ages are found for the ejecta blankets of Tycho and Copernicus craters than for their interior melt ponds and hummocky floors (e.g. Hiesinger et al., 2012). Such age discrepancies are sometimes due to the differing material properties of the target materials in which the superposing impact craters formed: higher absolute model ages are derived from weaker and more porous ejecta, in comparison to those derived from stronger and more competent regions, because smaller craters form in stronger and more porous target materials (e.g. van der Bogert et al., 2010). Thus, this is one possible explanation for the different model ages of the geologic units of Ninsar and the unnamed crater at $62^{\circ} \mathrm{N}$, $253^{\circ} \mathrm{E}$. It is also possible that seismic shaking induced by subsequent, nearby impacts could have continued to induce mass wasting within these craters long after they formed. Such seismic activity would result in protracted (if intermittent) mass wasting and resurfacing of the hummocky crater floor materials, which would partially reset their crater retention ages and thus cause them to have apparently younger absolute model ages than the corresponding ejecta deposits. Material on steeply sloping crater walls would be more likely to be dislodged by seismic shaking than material on less steeply sloping surfaces, which is consistent with the location of the hummocky crater floor materials within impact craters.

\subsubsection{Stratigraphically youngest period}

We interpret the talus material as having formed after the stratigraphically intermediate geologic units (Fig. 14), because it superposes the stratigraphically intermediate crater terrace material, hummocky crater floor material and lobate material knobby dark in craters such as Messor, Datan and Occator (see Section 3.2.7). We propose that seismic shaking from the formation of nearby younger impact craters triggered the mass wasting that formed the talus deposits in the host craters. Thus, the evolution of these craters continued into the stratigraphically youngest period.

\section{Conclusions}

Our geologic map of the Ezinu quadrangle illustrates that this region of Ceres is dominated by impact craters and impact-related geologic processes. The cratered terrain, which formed during the stratigraphically oldest period, is billions of years old. Impact craters such as Datan, Messor, Ninsar and Occator formed during the stratigraphically intermediate period, a few hundreds to tens of millions of years ago, and are surrounded by ejecta and contain hummocky materials and terraces. The evolution of some of these impact craters continued into the stratigraphically youngest period, with the deposition of talus. The restricted extents of dark and bright sub-units associated with the stratigraphically intermediate impact craters suggests that the dark/bright source materials may also have restricted extents within Ceres' subsurface, and/or that they tend to be more deeply buried than the intermediatealbedo source material. 
We interpret the lobate flows associated with Datan and Messor craters as evidence for water-ice-rich material within Ceres' subsurface. The lobate flows are only found in association with two impact craters in the entire quadrangle, indicating that the waterice-rich source material has restricted extents within Ceres' subsurface and/or may be so deeply buried that it is rarely excavated by impacts. The bright-spot-forming materials, brine precipitates and/or water ice, are also likely spatially restricted within Ceres' subsurface. Linear features are numerous and were likely formed by a diverse suite of processes, ranging from impact of locally and globally sourced material to collapse of surficial materials into subsurface fractures. The northern portion of Occator crater is situated within the Ezinu quadrangle, and thus our analysis of Ezinu provides context for the future investigation of Occator and its faculae, which have intrigued both the scientific community and the general public.

\section{Acknowledgments}

Part of the research was carried out at the Jet Propulsion Laboratory, California Institute of Technology, under a contract with the National Aeronautics and Space Administration. We thank Jim Skinner and Paul Byrne for the time they invested in making comments and edits to improve this manuscript. We thank the Dawn Flight Team at JPL for the development, cruise, orbital insertion and operations of the Dawn spacecraft at Ceres. We thank the instrument teams at the Max Planck Institute, German Aerospace Center (DLR), Italian National Institute for Astrophysics (INAF) and Planetary Science Institute (PSI) for the acquisition and processing of Dawn data.

\section{Supplementary materials}

Supplementary material associated with this article can be found, in the online version, at doi:10.1016/j.icarus.2017.10.038.

\section{References}

Ammannito, E., et al., 2016. Distribution of phyllosilicates on the surface of Ceres. Science 353 (6303) aaf4279-1-5.

Bland, M.T., et al., 2016. Composition and structure of the shallow subsurface of Ceres as revealed by crater morphology. Nat. Geosci. 9, 538-542.

Boyce, J., Barlow, N., Mouginis-Mark, P., Stewart, S., 2010. Rampart craters on Ganymede: Their implications for fluidized ejecta emplacement. Meteor. Planet. Sci. 45, 638-661.

Buczkowski, D.L., et al., 2018a. Geological mapping of the Ac-H-9 Occator quadrangle of Ceres from NASA's Dawn mission. Icarus in this volume.

Buczkowski, D.L., et al., 2018b. Tectonic analysis of fracturing associated with Occator crater. Icarus in review.

Buczkowski, D.L., et al., 2016. The geomorphology of Ceres. Science 353 (6303) aaf4332-1-8.

Buczkowski, D.L., Barnouin-Jha, O.S., Prockter, L.M., 2008. 433 Eros lineaments: global mapping and analysis. Icarus 193, 39-52.

Castillo-Rogez, J.C., McCord, T.C., 2010. Ceres' evolution and present state constrained by shape data. Icarus 205, 443-459.

Combe, J.-P., et al., 2018a. Exposed H2O-rich areas detected on Ceres with the Dawn Visible and InfraRed mapping spectrometer. Icarus in review.

Combe, J.-P., et al., 2018b. The Surface Composition of Ceres' Ezinu quadrangle analyzed by the Dawn mission. Icarus in revision.

Combe, J.-P., et al., 2016. Detection of local $\mathrm{H}_{2} \mathrm{O}$ exposed at the surface of Ceres. Science 353 (6303) aaf3010-1-6.

De Sanctis, M.C., et al., 2016. Bright carbonate deposits as evidence of aqueous alteration on Ceres. Nature 536, 54-57.

De Sanctis, M.C., et al., 2015. Ammoniated phyllosilicates with a likely outer solar system origin on (1) Ceres. Nature 528, 241-243.

De Sanctis, M.C., et al., 2011. The VIR spectrometer. Space Sci. Rev. 163, 329-369.

Drummond, J.D., et al., 2014. Dwarf planet Ceres: Ellipsoid dimensions and rotational pole from Keck and VLT adaptive optics images. Icarus 236, 28-37.

Ermakov, A.I., et al., 2017. Constraints on Ceres' internal structure and evolution from its shape and gravity measured by the Dawn spacecraft. J. Geophys. Res. Planet. 122, JE005302.

Federal Geographic Data Committee [Prepared for the Federal Geographic Data Committee by the U.S. geological Survey] 2006. FGDC Digital Cartographic Standard for Geologic Map Symbolization. Federal Geographic Data Committee, p. 290.
Ferrill, D.A., Wyrick, D.Y., Smart, K.J., 2011. Coseismic, dilational-fault and extension-fracture related pit chain formation in Iceland: Analog for pit chains on Mars. Lithosphere 3, 133-142.

Fu, R.R., 2017. The interior structure of Ceres as revealed by surface topography. Earth Planet. Sci. Lett. 476, 153-164.

Hayne, P.O., Aharonson, O., 2015. Thermal stability of ice on Ceres with rough topography. J. Geophys. Res. Planets 120, 1567-1584.

Hiesinger, H., et al., 2016. Cratering on Ceres: Implications for its crust and evolution. Science 353 (6303) aaf4759-1-8.

Hiesinger, H., et al., 2012. How old are young lunar craters? J. Geophys. Res. 117, E0OH10.

Hughson, K.H.G., et al., 2018. The Ac-5 (Fejokoo) quadrangle of Ceres: Geologic map and geomorphological evidence for ground ice mediated surface processes. Icarus this volume.

Jozwiak, L.M., Head, J.W., Wilson, L., 2015. Lunar floor-fractured craters as magmatic intrusions: Geometry, modes of emplacement, associated tectonic and volcanic features, and implications for gravity anomalies. Icarus 248, 424-447.

King, T.V.V., et al., 1992. Evidence for ammonium-bearing minerals on Ceres. Science 255, 1551-1553.

Kneissl, T., Michael, G.G., Schmedemann, N., 2016. Treatment of non-sparse cratering in planetary surface dating. Icarus 277, 187-195.

Kneissl, T., Michael, G.G., Platz, T., Walter, S.H.G., 2015. Age determination of linear surface features using the Buffered Crater Counting approach - Case studies of the Sirenum and Fortuna Fossae graben system on Mars. Icarus 250, 384-394.

Kneissl, T., van Gasselt, S., Neukum, G., 2011. Map-projection-independent crater size-frequency determination in GIS environments - New software tool for ArcGIS. Icarus 59, 1243-1254.

Konopliv, A.S., et al., 2011. The Dawn gravity investigation at Vesta and Ceres. Space Sci. Rev. 163, 461-486.

Krohn, K., et al., 2016. Cryogenic flow features on Ceres: Implications for crater-related cryovolcanism. Geophys. Res. Lett. 43, 11994-12003.

Krohn, K., et al., 2014. Mass movement on Vesta at steep scarps and crater rims. Icarus 244, 120-132.

Küppers, M., et al., 2014. Localized sources of water vapour on the dwarf planet (1) Ceres. Nature 505, 525-527.

Larson, H.P., Feierberg, M.A., Fink, U., Smith, H.A., 1979. Remote spectroscopic identification of carbonaceous chondrite mineralogies: Applications to Ceres and Pallas. Icarus 39, 257-271.

Lebofsky, L.A., et al., 1981. The 1.7- to $4.2-\mu \mathrm{m}$ spectrum of asteroid 1 Ceres: Evidence for structural water in clay minerals. Icarus 48, 453-459.

Li, J.-Y., et al., 2016. Surface albedo and spectral variability of Ceres. Astrophys. J. Lett. 817, L22.

Marchi, S., et al., 2016. The missing large impact craters on Ceres. Nat. Commun. 7 (12257), 1-9.

McCord, T.B., Sotin, C., 2005. Ceres: Evolution and current state. J. Geophys. Res. 110, E05009.

McCord, T.B., Gaffey, M.J., 1974. Asteroids: Surface composition from reflection spectroscopy. Science $186,352-355$.

Melosh, H.., 2011. Planetary Surface Processes. Cambridge University Press, p. 245.

Mest, S.C., et al., 2017. The global geologic map of Ceres based on dawn HAMO observations. In: Proceedings of the Lunar and Planetary Science Conference XLVIII Abstract 2512.

Michael, G.G., Kneissl, T., Neesemann, A., 2016. Planetary surface dating from crater size-frequency distribution measurements: Poisson timing analysis. Icarus 277, 279-285.

Michael, G.G., Platz, T., Kneissl, T., Schmedemann, N., 2012. Planetary surface dating from crater size-frequency distribution measurements: Spatial randomness and clustering. Icarus 218, 169-177.

Milliken, R.E., Rivkin, A.S., 2009. Brucite and carbonate assemblages from altered olivine-rich materials on Ceres. Nature Geosci. 2, 258-261.

Nathues, A., et al., 2017. Evolution of Occator Crater on (1) Ceres. Astron. J. 153, $112-1-12$.

Nathues, A., et al., 2016. FC color images of dwarf planet Ceres reveal a complicated geological history. Planetary Space Sci. 134, 122-127.

Nathues, A., et al., 2015. Sublimation in bright spots on (1) Ceres. Nature 528, 237-240.

Neesemann, A., et al., 2018. The various ages of Occator crater, Ceres: Results of a comprehensive synthesis approach. Icarus submitted.

Osinski, G.R., Tornabene, L.L., Grieve, R.A.F., 2011. Impact ejecta emplacement on terrestrial planets. Earth Planet. Sci. Lett. 310, 167-181.

Palomba, E., et al., 2018. Compositional differences among bright spots on the Ceres surface. Icarus in press.

Park, R.S., et al., 2016. A partially differentiated interior for (1) Ceres deduced from its gravity field and shape. Nature 537, 515-517.

Parker, J.W., et al., 2006. Ceres: High-resolution imaging with HST and the determination of physical properties. Adv. Space Res. 38, 2039-2042.

Prettyman, T.H., et al., 2011. Dawn's Gamma Ray and Neutron detector. Space Sci. Rev. $163,371-459$

Preusker, F., et al., 2016. Dawn at Ceres - shape model and rotational state. In: Proceedings of the Lunar and Planetary Science Conference XXXXVII Abstract 1954

Rivkin, A.S., Volquardsen, E.L., Clark, B.E., 2006. The surface composition of Ceres: discovery of carbonates and iron-rich clays. Icarus 185, 563-567.

Roatsch, T., et al., 2017. High-resolution Ceres Low Altitude mapping orbit atlas derived from Dawn Framing Camera images. Planet. Space Sci, 140, 74-79.

Roatsch, T., et al., 2016. High-resolution Ceres High Altitude Mapping Orbit atlas derived from Dawn Framing Camera images. Planet. Space Sci. 129, 103-107. 
Ruesch, O., et al., 2016. Cryovolcanism on Ceres. cience 353 (6303) aaf4286-1-8.

Russell, C.T., et al., 2016. Dawn arrives at Ceres: Exploration of a small volatile-rich world. Science 353 (6303), 1008-1010.

Schenk, P., et al., 2016. Impact cratering on the small planets Ceres and Vesta: S-C transitions, central pits and the origin of bright spots. In: Proceedings of the Lunar and Planetary Science Conference XXXXVII Abstract 2697.

Schmedemann, N., et al., 2017. The Distribution of Impact Ejecta on Ceres. In: Proceedings of the Lunar and Planetary Science Conference XLVIII Abstract 1233.

Schmedemann, N., et al., 2016. Timing of optical maturation of recently exposed material on Ceres. Geophys. Res. Lett. 43, 11987-11993.

Schmidt, B.E., et al., 2017. Geomorphological evidence for ground ice on dwarf planet Ceres. Nature Geosci. 10, 338-343.

Scully, J.E.C., et al., 2018. Ceres' Occator crater and its faculae explored through geologic mapping. Icarus in review.

Scully, J.E.C., et al., 2017. Evidence for the Interior Evolution of Ceres from Geologic Analysis of Fractures. Geophysical Research Letters 44, 9564-9572.

Scully, J.E.C., et al., 2015. Geomorphological evidence for transient water flow on Vesta. Earth Planet. Sci. Lett. 411, 151-163.

Scully, J.E.C., et al., 2014. Geomorphology and structural geology of Saturnalia Fossae and adjacent structures in the northern hemisphere of Vesta. Icarus 244, 23-40.

Schultz, P.H., 1976. Floor-fractured lunar craters. The Moon 15, 241-273.

Senft, L.E., Stewart, S.T., 2008. Impact crater formation in icy layered terrains on Mars. Meteoritics Planet. Sci. 43 (12), 1993-2013.
Sierks, H., et al., 2011. The Dawn Framing Camera. Space Sci. Rev. 163, 263-327. Sims, D.W., et al., 2003. Physical models of pit chain formation over dilational faults on Mars. In: Proceedings of the Lunar and Planetary Science Conference XXXIV Abstract 2099.

Stein, N., et al., 2018. The formation and evolution of bright spots on Ceres. Icarus in press.

Stephan, K., et al., 2017. An investigation of the bluish material on Ceres. Geophys. Res. Lett. 44, 1-9.

Thomas, C., et al., 2005. Differentiation of the asteroid Ceres as revealed by its Shape. Nature 437, 224-226.

van der Bogert, C.H., et al., 2010. Discrepancies between crater size-frequency distributions on ejecta and impact melt pools at lunar craters: An effect of differing target properties? In: Proceedings of the Lunar and Planetary Science Conference XXXXI Abstract 2165.

Williams, D.A., Buczkowski, D.L., Mest, S.C., Scully, J.E.C., 2018. Introduction: the geologic mapping of Ceres. Icarus this volume.

Williams, D.A., Yingst, R.A., Garry, W.B., 2014. Introduction: the geologic mapping of Vesta. Icarus 244, 1-12.

Wyrick, D., et al., 2004. Distribution, morphology, and origins of Martian pit crater chains. J. Geophys. Res. 109 E06005-1-20.

Yingst, R.A., et al., 2014. Geologic mapping of Vesta. Planet. Space Sci. 103, 2-23. 